\title{
Erythromycin oxidation and ERY-resistant Escherichia coli inactivation in urban wastewater by sulfate radical-based oxidation process under UV-C irradiation
}

\author{
I. Michael-Kordatou a ${ }^{\text {, M. Iacovou }}{ }^{\text {a }}$, Z. Frontistis ${ }^{\text {a }}$, E. Hapeshi ${ }^{\text {a }}$, D.D. Dionysiou ${ }^{\text {a, b }}$, \\ D. Fatta-Kassinos a, * \\ ${ }^{a}$ Department of Civil and Environmental Engineering and Nireas-International Water Research Centre, School of Engineering, University of Cyprus, P.O. Box \\ 20537, 1678 Nicosia, Cyprus \\ ${ }^{\mathrm{b}}$ Environmental Engineering and Science Program, University of Cincinnati, Cincinnati, OH 45221-0071, USA
}

\section{A R T I C L E I N F O}

\section{Article history:}

Received 21 July 2015

Received in revised form

26 August 2015

Accepted 27 August 2015

Available online 31 August 2015

\section{Keywords:}

Erythromycin

Antibiotic-resistant bacteria

Phytotoxicity

Sulfate radicals

Transformation products

\begin{abstract}
A B S T R A C T
This study evaluates the feasibility of UV-C-driven advanced oxidation process induced by sulfate radicals $\left(\mathrm{SO}_{4}{ }^{-}\right)$in degrading erythromycin (ERY) in secondary treated wastewater. The results revealed that $10 \mathrm{mg} \mathrm{L}^{-1}$ of sodium persulfate (SPS) can result in rapid and complete antibiotic degradation within 90 min of irradiation, while ERY decay exhibited a pseudo-first-order kinetics pattern under the different experimental conditions applied. ERY degradation rate was strongly affected by the chemical composition of the aqueous matrix and it decreased in the order of: ultrapure water $\left(k_{\text {app }}=0.55 \mathrm{~min}^{-1}\right)>$ bottled water $\left(k_{\text {app }}=0.26 \mathrm{~min}^{-1}\right)>$ humic acid solution $\left(k_{\text {app }}=0.05 \mathrm{~min}^{-1}\right)>$ wastewater effluents $\left(k_{\text {app }}=0.03 \mathrm{~min}^{-1}\right)$. Inherent $\mathrm{pH}$ conditions (i.e. $\left.\mathrm{pH} 8\right)$ yielded an increased ERY degradation rate, compared to that observed at $\mathrm{pH} 3$ and 5 . The contribution of hydroxyl and sulfate radicals $(\mathrm{HO} \cdot$ and $\mathrm{SO}_{4}{ }^{-}$) on ERY degradation was found to be ca. $37 \%$ and $63 \%$, respectively. Seven transformation products (TPs) were tentatively elucidated during ERY oxidation, with the 14-membered lactone ring of the ERY molecule being intact in all cases. The observed phytotoxicity against the tested plant species can potentially be attributed to the dissolved effluent organic matter $\left(\mathrm{dE}_{\mathrm{f}} \mathrm{OM}\right)$ present in wastewater effluents and its associated-oxidation products and not to the TPs generated from the oxidation of ERY. This study evidences the potential use of the UV-C/SPS process in producing a final treated effluent with lower phytotoxicity $(<10 \%)$ compared to the untreated wastewater. Finally, under the optimum experimental conditions, the UV-C/SPS process resulted in total inactivation of ERY-resistant Escherichia coli within $90 \mathrm{~min}$.
\end{abstract}

() 2015 Elsevier Ltd. All rights reserved.

\section{Introduction}

Urban wastewater treatment plants (UWTPs) are regarded as the main hotspots for antibiotics' and antibiotic-resistant bacteria and resistance genes (ARB\&ARG) spread into the environment (Rizzo et al., 2013a). It is widely accepted that conventional activated sludge (CAS) systems are inefficient in eliminating antibiotics, resulting thus in their environmental accumulation (Michael et al., 2013). In addition, the wastewater biological treatment stage itself, constitutes a reactor capable of promoting the horizontal

\footnotetext{
* Corresponding author.

E-mail address: dfatta@ucy.ac.cy (D. Fatta-Kassinos).
}

gene transfer of antibiotic resistance among bacteria (Rizzo et al., 2013a). The effects of these microcontaminants occurring in the effluent organic matter $\left(\mathrm{E}_{\mathrm{f}} \mathrm{OM}\right)$ of conventionally treated wastewater can potentially be even more pronounced when wastewater reuse schemes are implemented in water-scarce regions especially for agricultural irrigation (Michael-Kordatou et al., 2015). Antibiotics and ARB\&ARG can also reach surface water through wastewater discharges and consequently these can be introduced in drinking water and eventually in the food chain (Vaz-Moreira et al., 2014).

Recently, three macrolide antibiotics widely used in human medicine (i.e. erythromycin, clarithromycin and azithromycin) have been introduced into the special 'watch list' of substances known to potentially pose environmental implications to the aquatic 
environment for European Union-wide monitoring in the field of water policy pursuant to Directive 2008/105/EC of the European Parliament and of the Council (EU, 2015/495). The increasing scientific interest for this problem is also testified by the number of relevant European and international initiatives. In September 2014, a national strategy was announced by the White House that lays out measures to address the decreasing effectiveness of antibiotics for the treatment of bacterial infections and to mitigate the emergence and spread of ARB (The White House, 2014). Wastewater reuse and antibiotic resistance have also been placed as a top priority by the Environmental Monitoring Strategy Team of the European Committee on Standardisation (CEN/SABE, 2014). The proliferation of ARB\&ARG in the environment is a proven fact, but as highlighted in Berendonk et al. (2015), the environmental framework of resistance still lacks technological solutions to be applied for tackling this problem. A new European COST Action (ES1403) under the name NEREUS has recently initiated its activities with respect to the control of the propagation pathways of antibiotics and ARB\&ARG through wastewater reuse (FattaKassinos et al., 2015).

A number of studies have reported the occurrence of ERY in wastewater effluents after CAS or membrane bioreactor (MBR) treatment at concentrations of $n g \mathrm{~L}^{-1}-\mu \mathrm{g} \mathrm{L}^{-1}$ (Michael et al., 2013), as well in receiving environmental media upon discharge or reuse applications such as soil, groundwater and surface water (Muñoz et al., 2009). ERY has been shown to significantly inhibit the growth of aquatic photosynthetic organisms even at $\mu \mathrm{g} \mathrm{L}^{-1}$ concentrations (González-Pleiter et al., 2013). It has been reported to affect the photosynthesis process of Selenastrum capricornutum (e.g. photosynthetic rate, chlorophyll fluorescence, etc) at the concentration of $60 \mu \mathrm{g} \mathrm{L}^{-1}$ (Liu et al., 2011), while it has been found able to provoke negative effects on the growth of Lemna minor and Synechocystis sp. at concentrations ranging from 1 to $10 \mu \mathrm{g} \mathrm{L}^{-1}$ (Pomati et al., 2004). In addition, acute and chronic toxic effects of ERY towards various species have been reported (Ji et al., 2012; Nie et al., 2013). Moreover, bacterial strains harbouring resistance to ERY have been detected in various environmental compartments (Zhang et al., 2009). Thus, there is an imperative need to apply alternative advanced treatment technologies suitable to remove such microcontaminants from wastewater especially when the latter is intended for reuse.

A great scientific interest is being placed on the sulfate radical based-advanced oxidation processes (AOPs) due to their high efficiency in degrading a wide range of recalcitrant microcontaminants in aqueous matrices, including pharmaceuticals (Gao et al., 2012; Ghauch et al., 2012; Deng et al., 2013; Tan et al., 2013; Qi et al., 2014; Zhang et al., 2014), cyanotoxins (He et al., 2013), dyes (Frontistis et al., 2015), herbicides (Khan et al., 2013, 2014), bisphenol A (Olmez-Hanci et al., 2013), biocides (Nfodzo and Choi, 2011), chlorinated ethylene (Liang et al., 2007), etc. Sulfate radicals $\left(\mathrm{SO}_{4}{ }^{-}\right)$) have a significantly high reduction potential of $2.6 \mathrm{~V}$, slightly lower than that of $\mathrm{HO}$ (Gao et al., 2012) and can be produced by the activation of persulfate anion $\left(\mathrm{S}_{2} \mathrm{O}_{8}{ }^{2-}\right)$. Approaches of $\mathrm{S}_{2} \mathrm{O}_{8}{ }^{2-}$ activation include thermal (Ghauch et al., 2012) or microwave (Qi et al., 2014) treatment, UV irradiation (Gao et al., 2012) and addition of transition metals (Anipsitakis and Dionysiou, 2004) to produce $\mathrm{SO}_{4}{ }^{-}$, while a new approach of persulfate activation by quinones (i.e. functional moieties in natural organic matter) was recently proposed (Fang et al., 2013).

AOPs have been applied for the degradation of ERY through photolysis under simulated solar irradiation (Batchu et al., 2014), ozonation (Lin et al., 2009), Fenton oxidation (Chen et al., 2013) and $\mathrm{TiO}_{2}$ photocatalysis (Xekoukoulotakis et al., 2010). These studies however, were mainly focused on the effect of several experimental conditions on ERY degradation and mineralization, the latter being spiked at high concentration levels (i.e. $\mathrm{mg} \mathrm{L}^{-1}$ ) in various aqueous matrices (e.g. ultrapure water, seawater, etc.). Limited studies investigated the removal of ERY under real-world wastewater treatment conditions, including powdered activated carbon (PAC) adsorption $\left(\right.$ ERY $_{\text {removal }}=42-64 \%,[\mathrm{PAC}]=1 \mathrm{~g} \mathrm{~L}^{-1}$, Serrano et al., 2011), ozonation (ERY removal $=92 \%,\left[\mathrm{O}_{3}\right]=5-15 \mathrm{mg} \mathrm{L}^{-1}$, Ternes et al., 2003) and UV treatment (ERY removal = 24-34\%, $1.025 \mathrm{~mW} \mathrm{~cm}^{-2}[\lambda=254 \mathrm{~nm}$ ], Kim et al., 2009). According to the authors' knowledge, a study on ERY degradation in urban wastewater effluents and the abatement of ERY-resistant bacteria during the application of UV-driven persulfate oxidation process has not been reported yet.

Within this context, the current study investigated the efficiency of UV-C-activated persulfate process in degrading ERY at environmentally relevant concentration level $\left(\mu \mathrm{g} \mathrm{L}^{-1}\right)$ in urban wastewater. Special attention was paid to the optimization of the process with regard to various operating parameters such as oxidant dose, antibiotic initial concentration, solution $\mathrm{pH}$, presence or absence of UV-C irradiation, as well as the effect of the composition of various aqueous matrices. Thereafter, the main transformation products (TPs) of ERY formed in the different stages of oxidation were tentatively elucidated and a possible reaction pathway was proposed. Given the increasing interest in reusing urban wastewater in agricultural irrigation, the potential phytotoxicity of the treated samples towards three plant species was evaluated. Finally, the feasibility of the oxidation process in removing ERY-resistant Escherichia coli was assessed. This work is the first one revealing comprehensive data regarding the oxidation of ERY by UV-C-activated persulfate process, the elucidation of its main TPs, and finally the assessment of the process in removing phytotoxicity and ERY-resistant bacteria.

\section{Materials and methods}

\subsection{Chemicals}

The antibiotic reference standard $\left(\mathrm{C}_{37} \mathrm{H}_{67} \mathrm{NO}_{13}\right.$, CAS number 11407-8, Fluka) was of analytical grade and was used as received without further purification. Sodium persulfate ( $\mathrm{SPS}, \mathrm{Na}_{2} \mathrm{~S}_{2} \mathrm{O}_{8}$ ) was purchased by Sigma Aldrich. Methanol ( $\mathrm{MeOH}$, Sigma Aldrich) and anhydrous sodium sulfite $\left(\mathrm{Na}_{2} \mathrm{SO}_{3}\right.$, Sigma Aldrich) were used to quench the reactions in each sample for the chromatographic analysis and for the determination of the dissolved organic carbon (DOC), respectively. For the chromatographic analysis, LC/MS-grade $\mathrm{MeOH}$ (Sigma Aldrich) and formic acid (98\%, Fluka) were used. Ethanol (EtOH) and tert-butyl alcohol (t-BuOH), both supplied by Sigma Aldrich, were used for the quenching experiments. Humic acid (HA) was obtained from Sigma Aldrich. The $\mathrm{pH}$ of the treated solutions was adjusted to 7 with $2 \mathrm{~N} \mathrm{NaOH}$ (Merck) for the conduction of phytotoxicity and microbiological analyses. Tryptone Bile X-Glucuronide (TBX) medium agar was supplied by Sigma Aldrich for the enumeration of $E$. coli. Ultrapure water (Millipore, $18.2 \mathrm{M} \Omega \mathrm{cm}$ at $25^{\circ} \mathrm{C}$ ) was used throughout the experimental procedure and chromatographic analyses.

The oxidation experiments were performed in conventionally treated wastewater samples (the latter were collected from the secondary clarifier) taken from the UWTP at the University of Cyprus, which serves the student houses and offices of the campus (average flow $=400 \mathrm{~m}^{3} \mathrm{day}^{-1}$ ). All wastewater samples were grab samples collected in amber glass bottles ( $1 \mathrm{~L}$ each) and vacuum filtered through $0.45 \mu \mathrm{m}$ glass fibre filters (GF/D, Whatman, USA). The physicochemical parameters that have been used to characterize the wastewater samples prior to their use were determined according to the Standard Methods (Clesceri et al., 1998). The main average qualitative characteristics of the wastewater samples used 
during the experimental period were: $\mathrm{pH}=7.8$; conductivity $=$ $1465.6 \mu \mathrm{S} \mathrm{cm}^{-1} ;$ COD $=49 \mathrm{mg} \mathrm{L}^{-1} ; \mathrm{DOC}=7.9 \mathrm{mg} \mathrm{L}^{-1}$; $\mathrm{TSS}=30 \mathrm{mg} \mathrm{L}^{-1}$; total- $\mathrm{N}=25.4 \mathrm{mg} \mathrm{L}^{-1}$ and total-P $=4.5 \mathrm{mg} \mathrm{L}^{-1}$.

\subsection{Experimental setup and procedure}

ERY was spiked into the secondary treated wastewater effluents from a prepared standard aqueous solution to achieve an initial concentration of $100 \mu \mathrm{g} \mathrm{L}^{-1}$ (unless otherwise stated). It should be noted that the inherent concentration of ERY in the secondary wastewater samples used in this study was in the $\mathrm{ng} \mathrm{L}^{-1}$ range ([ERY $]_{\text {average }}=24-40 \mathrm{ng} \mathrm{L}^{-1}$ ), which practically did not have any substantial contribution to the overall antibiotic spiked concentration in the wastewater effluents.

The experiments were run in a photochemical apparatus consisting of an immersion well, batch type bench-scale cylindrical reaction vessel with a total capacity of $600 \mathrm{~mL}$ purchased from Ace Glass (Vineland, NJ, USA) and a $9 \mathrm{~W}$ low-pressure mercury lamp (Radium, Puritec, UVC-LPS 9, $\lambda=254 \mathrm{~nm}$ ). The photon flux of the lamp entering into the reaction system was quantified employing chemical actinometry with 2-nitrobenzaldehyde and it was found to be $4.57 \times 10^{-6}$ einstein $s^{-1}$ (Frontistis et al., 2015). The ERY spiked wastewater solution was introduced into the reaction vessel, and the UV-C lamp with its quartz glass sleeve was immersed inside the solution. The exterior of the reactor was completely wrapped with aluminium foil and was covered by a black cloth in order to prevent external light penetration during the experimental duration. A water jacket maintained the reaction temperature at $22 \pm 2{ }^{\circ} \mathrm{C}$ by circulating cooling water. Then, the appropriate amount of SPS was added to achieve the desired oxidant concentration in the range of $0-50 \mathrm{mg} \mathrm{L}^{-1}$. The solution was magnetically stirred to mix the reaction solution, and subsequently the UV-C lamp was turned on (time zero). At specific time intervals, samples were withdrawn from the reactor, transferred into vials with $\mathrm{MeOH}$ to quench further reactions and subsequently filtered through a $0.22 \mu \mathrm{m}$ syringe-driven filter prior to further analysis.

Each experiment was performed in triplicate and mean values are quoted as results. The error bars $(\leq 20 \%)$ in the figures represent the relative standard deviation (RSD) of three separate measurements.

\subsection{Analytical methods}

An ACQUITY TQD UPLC-MS ${ }^{2}$ system (Waters Corporation) equipped with a triple quadrupole mass spectrometer TQD (serial number QBA012) coupled with electrospray ionization (ESI) source was used to monitor the antibiotic concentration in the reaction solution and to tentatively elucidate the main transformation products (TPs) of ERY generated during the oxidation process. Data acquisition was performed with positive ESI in multiple reaction monitoring mode (MRM), recording the transitions between the precursor ion $(\mathrm{m} / \mathrm{z} 734.7)$ and the most abundant fragment ions. The most abundant transition product ion $(Q, m / z 158)$ was used for quantification of the target compound, while the second transition product $(q, m / z 576)$ together with the ratio of the intensities of the two MS transitions $(Q / q)$ were used for confirmation purposes. Column BEH Shield RP18 $(1.7 \mu \mathrm{m} ; 2.1 \times 50 \mathrm{~mm}$; Waters $)$ was employed for the chromatographic analysis with mobile phase consisting of water $+0.1 \%$ formic acid (eluent $\mathrm{A}$ ) and methanol (eluent B). The elution gradient was 5\% B (0 min), 5\% B (1.5 min), $30 \%$ B ( 2 min ), 50\% B (3 min), 70\% B (5 min), 90\% B (6 min), 90\% B (7 min), 5\% B (7.1 min) and 5\% B (9 min). The LC-MS ${ }^{2}$ analysis conditions were: $\mathrm{T}_{\text {column }}=40{ }^{\circ} \mathrm{C}$, flow rate $=0.3 \mathrm{~mL} \mathrm{~min}^{-1}$, cone voltage $=35 \mathrm{~V}$, injection volume $=10 \mu \mathrm{L}$ and run time $=9 \mathrm{~min}$. All MS data was processed using the software package MassLynx V4.1.
A relatively high amount of the antibiotic $\left(10 \mathrm{mg} \mathrm{L}^{-1}\right)$ was used for the determination of its TPs formed during the oxidation process, which enabled obtaining slow degradation kinetics and provided favourable conditions for the determination of TPs. Prior to TPs analysis, the treated samples were extracted by means of solidphase extraction (SPE) using Oasis HLB cartridges $(60 \mathrm{mg} / 3 \mathrm{cc}$, Waters Corporation). The cartridges were conditioned with $5 \mathrm{~mL}$ of $\mathrm{MeOH}$ and $5 \mathrm{~mL}$ of ultrapure water $(\mathrm{pH} 3)$ at a flow rate of $1 \mathrm{~mL} \mathrm{~min}^{-1}$. Then, $10 \mathrm{~mL}$ of the sample were percolated through the cartridges at a flow rate of $1 \mathrm{~mL} \mathrm{~min}^{-1}$ followed by $5 \mathrm{~mL}$ of deionized water. The cartridges were then dried under vacuum and final elution was performed with $8 \mathrm{~mL}$ of $\mathrm{MeOH}$ at $1 \mathrm{~mL} \mathrm{~min}^{-1}$. The extracts were concentrated by solvent evaporation with a gentle stream of nitrogen and then reconstituted to a final volume of $1 \mathrm{~mL}$ in $\mathrm{MeOH} /$ water (5:95\%, v:v) prior to instrumental analysis. The sample extracts $(20 \mu \mathrm{L})$ were directly injected into the UPLC-MS ${ }^{2}$ system.

An Aurora 1030 W TOC analyser was employed in order to monitor the dissolved organic carbon (DOC) in the treated samples and therefore, to assess the extent of mineralization.

\subsection{Phytotoxicity assessment}

The phytotoxicity of the treated samples was evaluated towards Sorghum saccharatum, Lepidium sativum and Sinapis alba using the Phytotestkit microbiotest (MicroBioTests Inc.). The bioassay procedure is described in detail elsewhere (Michael et al., 2012).

\subsection{Enumeration of total cultivable and ERY-resistant E. coli}

E. coli enumeration was carried out using a membrane filtration apparatus as described by Novo and Manaia (2010). The bacteria were enumerated on TBX agar or on this medium supplemented with ERY. The antibiotic concentration in the culture medium $\left(100 \mu \mathrm{g} \mathrm{L}^{-1}\right)$ was chosen based on its environmental relevance and its minimum inhibitory concentration (MIC) to E. coli (European Committee on Antimicrobial Susceptibility Testing, EUCAST). All samples were obtained using aseptic techniques and sterile materials. Serial dilutions of the treated samples were done in saline solution $(\mathrm{NaCl} 0.85 \%)$ and passed through cellulose ester membranes $(0.45 \mu \mathrm{m}$ pore size, Millipore) to ensure a reliable count in each sampling time. Then, the membranes were placed onto the culture media and incubated for $24 \mathrm{~h}$ at $44{ }^{\circ} \mathrm{C}$. After the incubation period, the blue-coloured colony forming units (CFU) on the TBX agar were enumerated and further counted. The limit of detection (LOD) for $E$. coli was $1 \mathrm{CFU} \mathrm{mL} \mathrm{m}^{-1}$, while the average inherent $E$. coli concentration in the wastewater effluents was $9.2 \times 10^{5} \mathrm{CFU} \mathrm{mL}{ }^{-1}$. The prevalence of ERY-resistant $E$. coli was calculated as the ratio between the CFU $\mathrm{mL}^{-1}$ observed on antibiotic supplemented culture medium and the CFU mL $\mathrm{mL}^{-1}$ observed on the same medium without antibiotic (Resistance $\left.(\%)=\frac{C F U L^{-1} \text { medium with } E R Y}{C F U ~ m L^{-1} \text { medium without } E R Y} \times 100\right)$.

\section{Results and discussion}

\subsection{Degradation of ERY during UV-C activated persulfate oxidation} under various experimental conditions

\subsubsection{Effect of SPS concentration on ERY degradation - degradation kinetics}

To obtain the optimum oxidant dose for the substrate degradation, a series of experiments was carried out with several concentration levels of SPS. Fig. 1 (a) depicts the effect of SPS initial concentration on the degradation of ERY (expressed as normalized concentration $[E R Y] /[E R Y]_{0}$ ) as a function of reaction time. The 
(a)

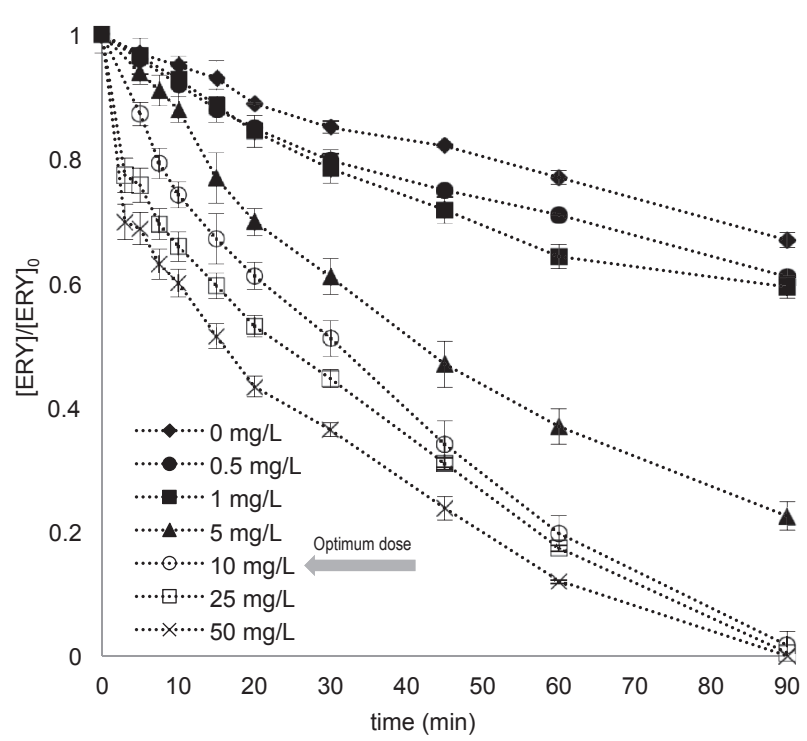

(b)

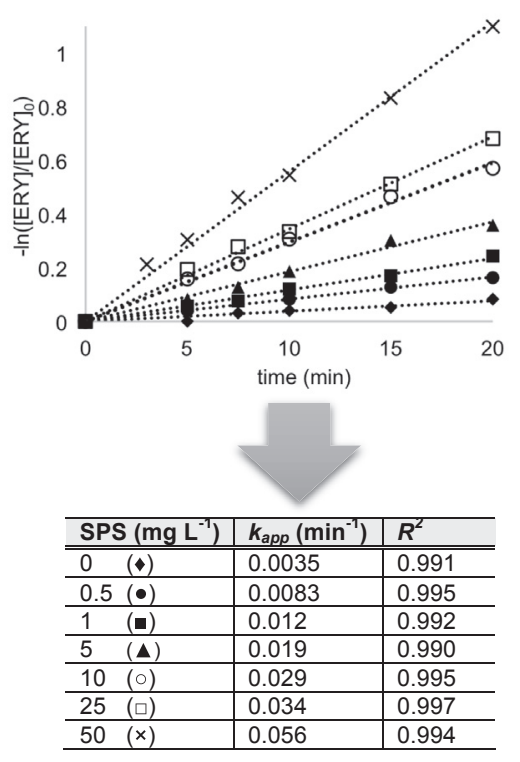

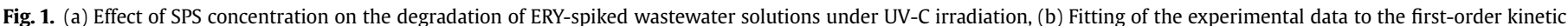

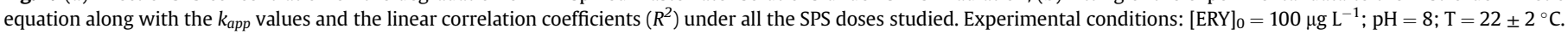

initial concentration of SPS was altered from 0 to $50 \mathrm{mg} \mathrm{L}^{-1}$, while the initial concentration of the antibiotic was kept constant $\left([E R Y]_{0}=100 \mu \mathrm{g} \mathrm{L}^{-1}\right)$ in each experimental run. The results clearly demonstrated that the degradation of ERY was significantly enhanced with increasing the oxidant concentration from 0.5 to 1 and then to $5 \mathrm{mg} \mathrm{L}^{-1}$ i.e. $38 \%, 41 \%, 70 \%$, while a $100 \%$ degradation was achieved within 90 min of irradiation when the SPS concentration was 10,25 and $50 \mathrm{mg} \mathrm{L}^{-1}$. This is attributed to the rapid formation of both $\mathrm{SO}_{4}{ }^{-}$and $\mathrm{HO} \cdot$ (the latter are formed during the reaction of $\mathrm{SO}_{4}{ }^{-}$with water). The photolytic experiments (UV-C irradiation alone, $[\mathrm{SPS}]=0 \mathrm{mg} \mathrm{L}^{-1}$ ) yielded approximately $34 \%$ of ERY degradation after 90 min of treatment. According to Keen and Linden (2013), ERY is not susceptible to direct photolysis $(<15 \%$

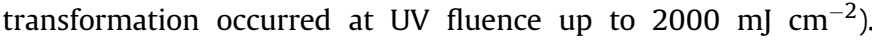
Several studies have reported that beyond a certain level, an increase in the initial SPS dose cannot cause an increase in the substrate removal because $\mathrm{S}_{2} \mathrm{O}_{8}{ }^{2-}$ itself can act as a scavenger of $\mathrm{HO}$ and $\mathrm{SO}_{4}{ }^{-}{ }^{-}$(Qi et al., 2014; Saien et al., 2014). Nevertheless, in this study the inhibition effect of SPS was not observed, probably because the highest SPS dose (i.e. $50 \mathrm{mg} \mathrm{L}^{-1}$ ) did not reach the critical inhibition level that could quench the produced radicals and slow down ERY degradation. This behaviour was also observed during the degradation of sulfamethazine and carbamazepine upon UV-activated persulfate oxidation (Gao et al., 2012; Deng et al., 2013; Zhang et al., 2014). Under the various SPS concentrations studied herein, DOC measurements showed no significant mineralization of the treated solution after $90 \mathrm{~min}$ of irradiation $\left(\right.$ DOC $\left._{\text {removal }}=35 \%\right)$, implying a considerable residual organic load which may be due to the presence of recalcitrant oxidation products less susceptible towards $\mathrm{HO}^{\cdot}$ and $\mathrm{SO}_{4}{ }^{-}$attack. Here it is noted that the DOC of the reaction solution corresponds to the inherent DOC of the wastewater effluents (i.e. DOC $\approx 8 \mathrm{mg} \mathrm{L}^{-1}$ ) taking into consideration the low concentration of the spiked antibiotic (100 $\mu \mathrm{g} \mathrm{L}^{-1}$ of ERY correspond to less than $0.1 \mathrm{mg} \mathrm{L}^{-1}$ of DOC).

The degradation of ERY during the oxidation process followed pseudo-first-order kinetics and this was confirmed by the linear behaviour of $-\ln \left([E R Y] /[E R Y]_{0}\right)$ (where $[E R Y]_{0}$ and [ERY] refer to the concentrations of the antibiotic at times 0 and $t(\mathrm{~min})$, respectively), as a function of the treatment time in all the experiments performed. The apparent rate constant $k_{a p p}\left(\mathrm{~min}^{-1}\right)$ was obtained from the slope of the linear plots. It is noted that this kinetic expression is acceptable at early times of treatment (a pseudo-steady-state concentration of the produced radicals in the reaction solution can be assumed), to minimize competitive reactions that may occur due to the accumulation of the new organic compounds formed upon the oxidation of both the parent compound and the dissolved effluent organic matter $\left(\mathrm{dE}_{\mathrm{f}} \mathrm{OM}\right)$ (Michael et al., 2012). Fig. 1 (b) shows the experimental data fitting in the first-order kinetic equation along with the $k_{a p p}$ values and the linear correlation coefficients $\left(R^{2}\right)$ under all the SPS concentrations studied herein. The high values of $R^{2}(>0.99)$ revealed that ERY degradation by the UV-C/SPS process was consistent with pseudofirst-order kinetics. It is also evident that $k_{a p p}$ increased from $3.5 \times 10^{-3} \mathrm{~min}^{-1}$ to $5.6 \times 10^{-2} \mathrm{~min}^{-1}$ when SPS dose increased from 0 to $50 \mathrm{mg} \mathrm{L}^{-1}$.

It is important to point out that to render the oxidation system effective, it is essential that its application represents a low cost operation, which basically implies a better control of SPS dosage. An oxidant concentration of $10 \mathrm{mg} \mathrm{L}^{-1}$ was chosen as the optimum dose and used in further experiments, as this concentration is able to achieve rapid and complete degradation of the examined substrate, and in order to avoid working with higher oxidant concentration (25-50 $\mathrm{mg} \mathrm{L}^{-1}$ ) associated with higher operational cost. Here it is noted that at the optimum oxidant concentration in the absence of UV-C irradiation (dark conditions), a significantly lower degradation of the antibiotic was achieved within $90 \mathrm{~min}$ (75\%), due to the lower amount of radicals in the reaction solution.

\subsubsection{ERY degradation in different aqueous matrices}

Additional experiments were performed aiming at evaluating the effect of the aqueous matrix composition on the degradation of ERY under UV-C irradiation in the presence of the optimum SPS concentration (i.e. $[\mathrm{SPS}]=10 \mathrm{mg} \mathrm{L}^{-1}$ ). The experimental approach to assess the matrix effect on the process efficiency was first designed with non-complex aqueous matrices (ultrapure water [UPW], bottled water [BW]), and then with matrices of increased 
complexity by studying synthetic humic acid solution (HA, $10 \mathrm{mg} \mathrm{L}^{-1}$ ) and finally secondary treated wastewater effluents (WW). As indicated in Fig. 2, different ERY degradation profiles were observed among the aqueous matrices, although ERY was completely degraded in all of them. The extent of ERY degradation rate decreases in the order of: UPW $>\mathrm{BW}>\mathrm{HA}>\mathrm{WW}$. The time needed for the complete degradation of ERY was higher in the case of BW (60 min) compared to UPW (30 min), and this was also confirmed by the $k_{a p p}$ values obtained in both cases ( 0.55 and $0.26 \mathrm{~min}^{-1}$ for UPW and BW, respectively). This may be ascribed to the interferences by inorganic ions (e.g. carbonate and bicarbonate ions) present in BW, which can act as scavengers of $\mathrm{SO}_{4}{ }^{-}$and $\mathrm{HO}$, rendering thus ERY removal quite slow (Sirtori et al., 2010). In addition, the substrate degradation rate was appreciably higher in UPW than in WW indicating the negative effect of the WW complex composition on the degradation rate of ERY. $\mathrm{dE}_{\mathrm{f}} \mathrm{OM}$ present in WW was shown to decrease the antibiotic degradation rate, since it can compete for light absorption and can act as $\mathrm{SO}_{4}{ }^{-}$and $\mathrm{HO} \cdot$ scavenger. In addition, WW contains inorganic species (e.g. chlorides, bicarbonates) which can rapidly react with $\mathrm{SO}_{4}{ }^{-}$and $\mathrm{HO}$, resulting thus in reduced process efficiency (Sirtori et al., 2010).

Interestingly, when switching from WW to HA solution, the degradation rate of ERY in the latter was much higher compared to that observed in WW, and this can be possibly attributed to the effective activation of SPS by the quinone functional groups of HA through a semiquinone anion radical mechanism reaction, leading to an enhanced degradation (Fang et al., 2013). Fang et al. (2013) elucidated a new pathway of persulfate activation due to the comproportionation reaction between quinone and hydroquinone, leading to the formation of semiquinone radicals, which in turn induce persulfate activation to further produce $\mathrm{SO}_{4}{ }^{-}$. In addition, humic-based compounds in the presence of irradiation at $254 \mathrm{~nm}$ favour the generation of hydrated electrons, which can be further converted into HO• in the presence of oxygen (Khan et al., 2013). Of course, the presence of HA prompted an inhibitory effect on the antibiotic degradation, as both the removal and the degradation rate constant of ERY were lower compared to those observed in UPW. Similar observations were reported in Zhang et al. (2014), indicating that the inhibition effect on the degradation of carbamazepine was not pronounced in the presence of HA at low concentration level (i.e. $1-10 \mathrm{mg} \mathrm{L}^{-1}$ ). Tan et al. (2013) observed that the degradation rate of antipyrine during the UV/SPS oxidation increased from 1.66 to $1.97 \mathrm{~h}^{-1}$ as the HA concentration increased from 0 to $2.5 \mathrm{mg} \mathrm{L}^{-1}$, but gradually dropped to $1.6 \mathrm{~h}^{-1}$ when HA increased to $10 \mathrm{mg} \mathrm{L}^{-1}$. The degradation of ciprofloxacin under SPSbased processes in both distilled water and wastewater was shown to be moderately affected in the presence of $\mathrm{HA}\left(10 \mathrm{mg} \mathrm{L}^{-1}\right)$ (Mahdi-Ahmed and Chiron, 2014).

The above findings regarding the effect of HA and WW on ERY degradation could be linked to a very interesting conclusion. Since WW contains humic acid-associated compounds, it may be assumed that the higher inhibition effect of WW on the antibiotic degradation compared to HA, can be mainly attributed to the presence of soluble microbial products (SMPs), which constitute the main portion of $\mathrm{dE}_{\mathrm{f}} \mathrm{OM}$, consisting of organic compounds with unsaturated bonds that can react readily with $\mathrm{SO}_{4}{ }^{-}$and $\mathrm{HO} \cdot$ during the oxidation process (Michael-Kordatou et al., 2015). Recently, Mahdi-Ahmed and Chiron (2014) reported that $\mathrm{SO}_{4}{ }^{-}$) can react selectively against organic compounds which are usually rich in heteroatoms (i.e. nitrogen) through an electron transfer oxidation mechanism. Since nitrogen-containing organic compounds (i.e. dissolved organic nitrogen) prevail in SMPs, the latter are suspected to have a high $\mathrm{SO}_{4}{ }^{-}$reactivity hindering thus the antibiotic degradation. Noteworthy, however, is that the above statement is merely hypothetical and further research will be needed to back up and confirm this hypothesis.

\subsubsection{Effect of solution $\mathrm{pH}$ on the degradation of ERY}

Solution $\mathrm{pH}$ is another key experimental parameter which can greatly influence the performance of the oxidation processes by altering the radical's speciation and concentration in the reaction solution. pH can affect in a different manner the oxidation of different substrates (depending on substrates' structural characteristics) and therefore the $\mathrm{pH}$ effect usually cannot be predicted. In order to elucidate the effect of $\mathrm{pH}$ on the ERY degradation, experiments were carried out at various $\mathrm{pH}$ levels in the range of 3-8. Here it is noted that the inherent $\mathrm{pH}$ of the ERY spiked wastewater solutions was approximately 8.

Fig. 3 displays the time-dependent profiles of ERY degradation as a function of the initial $\mathrm{pH}$ at the optimum oxidant concentration $\left([S P S]=10 \mathrm{mg} \mathrm{L}^{-1}\right)$. The results revealed that the antibiotic degradation was strongly $\mathrm{pH}$-dependent, with the substrate

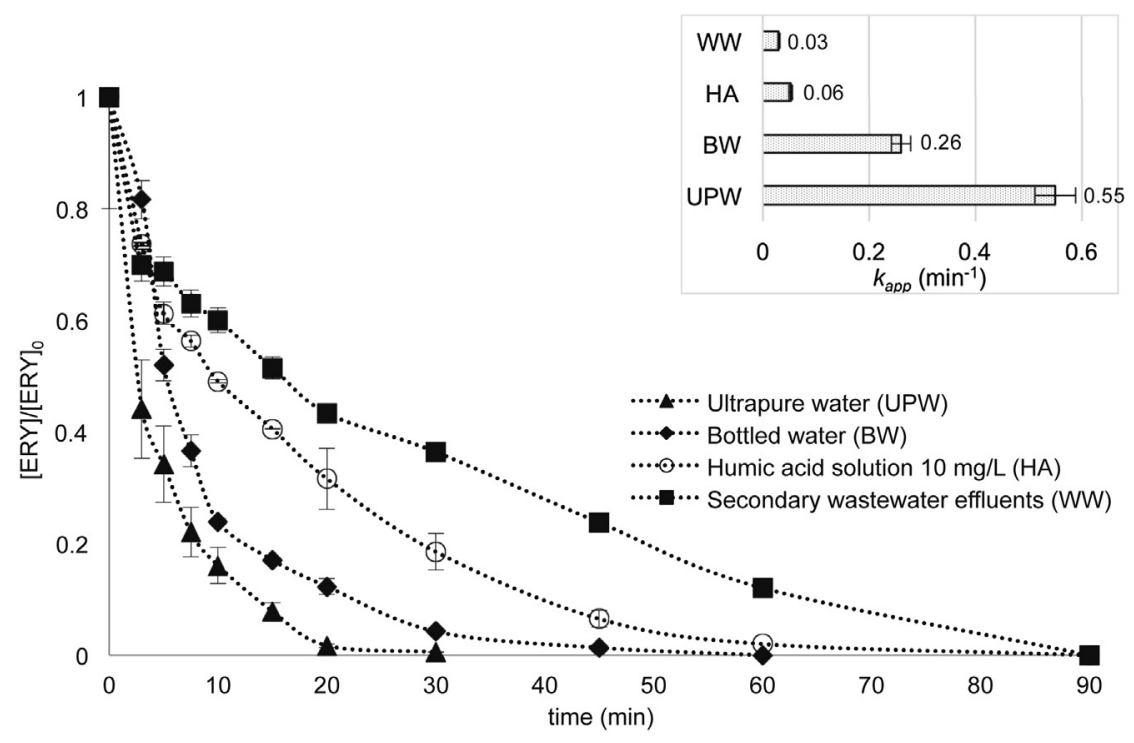

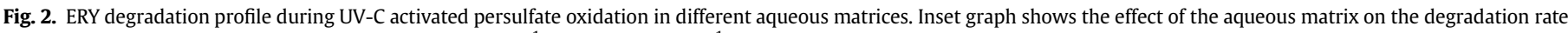
constant, $k_{a p p}$. Experimental conditions: $[\mathrm{ERY}]_{0}=100 \mu \mathrm{g} \mathrm{L}^{-1} ;[\mathrm{SPS}]_{0}=10 \mathrm{mg} \mathrm{L}^{-1} ; \mathrm{pH}=8 ; \mathrm{T}=22 \pm 2{ }^{\circ} \mathrm{C}$. 


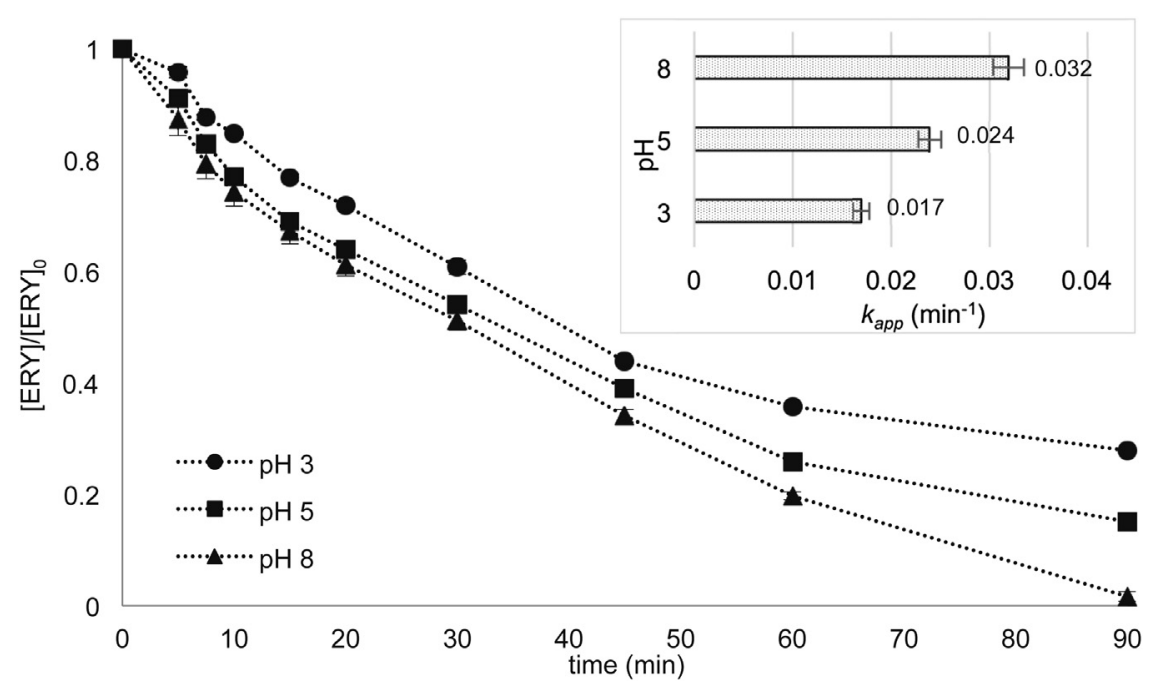

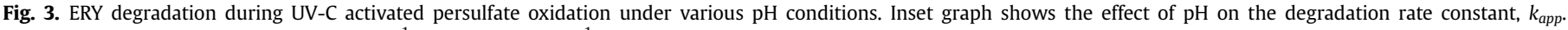
Experimental conditions: $[\mathrm{ERY}]_{0}=100 \mu \mathrm{g} \mathrm{L}^{-1} ;[\mathrm{SPS}]_{0}=10 \mathrm{mg} \mathrm{L}^{-1} ; \mathrm{T}=22 \pm 2{ }^{\circ} \mathrm{C}$.

degradation being reinforced at $\mathrm{pH}$ 8. Also, from the inset of Fig. 3, it is apparent that ERY degradation rate constant was raised with increasing solution $\mathrm{pH}$, revealing that the degradation process was more favourable in mild alkaline conditions. ERY removal was higher at pH $8(100 \%)$ than at $\mathrm{pH} 5$ or $3(85 \%$ and $73 \%$, respectively), while the corresponding degradation rate constants were 0.032 , 0.024 and $0.017 \mathrm{~min}^{-1}$, respectively. At alkaline $\mathrm{pH}$ conditions, $\mathrm{SO}_{4}{ }^{-}$- undergo transformation reactions generating additional $\mathrm{HO} \cdot$, in accordance with Eq. (1), which in turn can provoke an accelerated SPS decomposition yielding additional radicals (Liang et al., 2007; Gao et al., 2012; Deng et al., 2013). Also, the formed HO• potentially increase the degradation rate since they have a higher redox potential and a less-selective reactivity to substrate degradation than $\mathrm{SO}_{4}{ }^{-}$.

$\mathrm{SO}_{4}^{--}+\mathrm{HO}^{-} \rightarrow \mathrm{SO}_{4}^{2-}+\mathrm{HO}^{\circ}$

Under acidic conditions ( $\mathrm{pH} 3$ and 5), part of $\mathrm{SO}_{4}{ }^{-}$can react with various ions present in the wastewater matrix, yielding radicals with lower oxidation potential. Also, it was reported that low pH can slow down SPS decomposition (Qi et al., 2014).

The above findings are in accordance with the study of Qi et al. (2014) who investigated the influence of pH on the degradation of sulfamethoxazole by microwave-activated persulfate oxidation indicating that its degradation rate constant was higher at $\mathrm{pH} 8$. Also, a similar finding was reported by Guan et al. (2011) during the degradation of benzoic acid in a $U_{254 n m} /$ peroxymonosulfate system. Tan et al. (2013) also observed the positive contribution of alkaline $\mathrm{pH}$ with respect to the degradation of antipyrine during the UV/SPS process, who found that the rate constant was dramatically increased from $1.346 \mathrm{~h}^{-1}$ to $2.005 \mathrm{~h}^{-1}$ with the increasing $\mathrm{pH}$ from 2.5 to 11.5 . In Liang et al. (2007), trichloroethylene degradation during the thermal activation of SPS was enhanced at $\mathrm{pH} 7$, while at higher $\mathrm{pH}$ (above neutral values) the process efficiency was considerably diminished.

Noteworthy is that the influence of $\mathrm{pH}$ on the degradation of ERY in the UV-C/SPS system is a complex issue since it concerns not only the generation of $\mathrm{SO}_{4}{ }^{-}$and $\mathrm{HO} \cdot$, but also the ionization state of the substrate $\left(p K_{\mathrm{a}}\right)$ during the process, whose $p K_{a}$ is 7.74-8.9 (Babic et al., 2007; Batchu et al., 2014). Considering the structure of the ERY molecule and that the inherent $\mathrm{pH}$ of wastewater falls within the range of its $p K_{a}$ value, it may be assumed that the antibiotic exists predominantly in its deprotonated form at $\mathrm{pH}$ 8. Here it is noted that ERY does not contain unsaturated $\mathrm{C}-\mathrm{C}$ bonds that both radicals would preferentially attack via an electrophilic mechanism. Thus, the effect of solution $\mathrm{pH}$ on ERY degradation can be associated with various non-determined herein complex reactions.

\subsubsection{Effect of the initial antibiotic concentration}

In further experiments, the effect of the initial antibiotic concentration on the UV-C/SPS process efficiency was examined in the range of $50-200 \mu \mathrm{g} \mathrm{L}^{-1}$ at the optimum oxidant concentration ([SPS $\left.]_{0}=10 \mathrm{mg} \mathrm{L}^{-1}\right)$. The complete degradation of ERY was realized within $70 \mathrm{~min}$ at $50 \mu \mathrm{g} \mathrm{L}^{-1}$ and in $90 \mathrm{~min}$ at $100 \mu \mathrm{g} \mathrm{L}^{-1}$, while at the highest concentration of $200 \mu \mathrm{g} \mathrm{L}^{-1}$ the substrate degradation was reduced to $85 \%$ within $90 \mathrm{~min}$ of irradiation (data not shown). Additionally, it was observed that the degradation rate constant decreased with increasing initial concentration of the substrate from $50 \mu \mathrm{g} \quad \mathrm{L}^{-1}\left(k_{a p p}=0.041 \mathrm{~min}^{-1}\right)$ to $200 \mu \mathrm{g} \mathrm{\textrm {L } ^ { - 1 }}$ $\left(k_{\text {app }}=0.019 \mathrm{~min}^{-1}\right)$. The presumed reason is that at lower initial substrate concentration, the higher ratio of $\mathrm{SO}_{4}{ }^{-}$and $\mathrm{HO} \cdot$ to ERY provided a potentially greater probability for ERY molecules being attacked by both radicals, leading thus to higher $k_{a p p}$ values.

\subsection{Assessment of the contribution of $\mathrm{SO}_{4}{ }^{-}$and $\mathrm{HO} \cdot$ in the degradation of ERY}

To gain further insight into the reaction mechanism, quenching experiments using specific probes, such as ethanol (EtOH) and tert-butyl alcohol (t-BuOH), were carried out to identify the contribution of $\mathrm{SO}_{4}{ }^{-}$and $\mathrm{HO} \cdot$ in degrading ERY in the UV-C activated persulfate system. EtOH and t-BuOH have been extensively used in previous studies for $\mathrm{SO}_{4}{ }^{-}$and $\mathrm{HO}$ - identification (Anipsitakis and Dionysiou, 2004; Saien et al., 2014; Zhang et al., 2014). EtOH was reported to readily react with both radicals $\left(k_{\mathrm{EtOH}-\mathrm{SO}_{4}^{-}}=1.6-7.7 \times 10^{7} \mathrm{M}^{-1} \mathrm{~s}^{-1}\right.$ and $k_{\mathrm{EtOH}-\mathrm{HO}}=1.2-2.8 \times$ $10^{9} \mathrm{M}^{-1} \mathrm{~s}^{-1}$; the reaction rate with $\mathrm{HO} \cdot$ is approximately 50 -fold higher than that with $\mathrm{SO}_{4}{ }^{-}$), whereas t-BuOH can mainly scavenge $\mathrm{HO} \cdot$ and poorly react with $\mathrm{SO}_{4}{ }^{-}\left(k_{t-\mathrm{BuOH}-\mathrm{SO}_{4}^{-}}=4-9.1 \times 10^{5} \mathrm{M}^{-1} \mathrm{~s}^{-1}\right.$ and $k_{t-\mathrm{BuOH}-\mathrm{HO}}=3.8-7.6 \times 10^{8} \mathrm{M}^{-1} \mathrm{~s}^{-1}$; the reaction rate with $\mathrm{HO} \cdot$ is approximately 1000 -fold higher than that with $\mathrm{SO}_{4}{ }^{-}$) (Anipsitakis and Dionysiou, 2004). 
EtOH and t-BuOH were added in the reaction solution to obtain a concentration of $20 \mathrm{mM}$, which corresponds to a 500:1 M ratio of the alcohol versus the oxidant. This was done in order to sufficiently quench the generated radicals. Fig. 4 illustrates the influence of both radical scavengers on the degradation of ERY. It is clearly shown that in the absence of alcohol (case $\boldsymbol{A}$ ), ERY was completely removed due to the synergistic action of both $\mathrm{SO}_{4}{ }^{-}$and $\mathrm{HO}$. Nevertheless, the addition of EtOH (case B) and t-BuOH (case C) led to a remarkably lower degradation of ERY to $25 \%$ and $63 \%$ within 90 min, respectively, compared to the degradation observed in the absence of both scavengers. Both radicals were scavenged when EtOH was added in the solution which resulted in slower degradation of the substrate, whereas in the presence of $\mathrm{t}-\mathrm{BuOH}$, ERY degradation was attributed to $\mathrm{SO}_{4}{ }^{-}$, since the latter were poorly quenched by t-BuOH. Accordingly, the contribution of $\mathrm{HO} \cdot$ to the substrate degradation can be elucidated by comparing the difference between the process efficiency (in terms of ERY degradation) in cases $\boldsymbol{A}$ and $\boldsymbol{C}$. These results imply that both types of radicals are indeed responsible for the degradation of ERY, whereas $\mathrm{SO}_{4}{ }^{-}$- seem to be the primary species formed. This observation was consistent with previous studies, where $\mathrm{SO}_{4}{ }^{-}$- were found to be the predominant radicals during the persulfate oxidation of various organic compounds (Saien et al., 2014; Zhang et al., 2014). In a recent study of Monteagudo et al. (2015), the contribution of $\mathrm{SO}_{4}{ }^{-}$ and $\mathrm{HO}^{*}$ on the degradation of carbamazepine during the UVactivated persulfate oxidation was determined using methanol $(\mathrm{MeOH})$ and $\mathrm{t}-\mathrm{BuOH}$. Their results revealed that both radicals were indeed involved in the oxidation reactions, with $\mathrm{SO}_{4}{ }^{-}$- being the main oxidant species. Also, as pointed by Lin and $\mathrm{Wu}(2014), \mathrm{SO}_{4}{ }^{-}$ dominated in the oxidation of ciprofloxacin during the $\mathrm{UV} / \mathrm{S}_{2} \mathrm{O}_{\mathrm{s}}{ }^{2-}$ process.

\subsection{Identification of the main transformation products (TPS) and proposed transformation pathway of ERY during UV-C/SPS oxidation}

Schematic 1 depicts the proposed chemical structures and the exact mass values of the main TPs identified during the degradation of ERY by UV-C/SPS process alongside the tentative elucidation pathway. The screening of the photo-treated samples in $(+)$ ESI mode allowed the identification of seven TPs with different $\mathrm{m} / \mathrm{z}$ ratios (i.e. TP325, TP690, TP702, TP718, TP720, TP748, and TP750) and with their peaks being greater than $15 \%$ of the highest peak intensity. The interpretation/verification of the unknown structures of the detected TPs was accomplished employing three different approaches of mass spectrometry; full scan, selected ion ratio (SIR) and multiple reaction monitoring (MRM) mode. The fragment ions obtained during the $\mathrm{MS}^{2}$ measurements allowed the identification and a plausible structure of the potentially formed TPs, based on the fragmentation pattern of the ERY molecule, which produced $\mathrm{m} /$ $z \quad 576.58\left(\mathrm{C}_{29} \mathrm{H}_{54} \mathrm{NO}_{10}\right), m / z \quad 558.55\left(\mathrm{C}_{29} \mathrm{H}_{52} \mathrm{NO}_{9}\right), \quad m / z \quad 522.21$ $\left(\mathrm{C}_{29} \mathrm{H}_{48} \mathrm{NO}_{7}\right)$ and $\mathrm{m} / z 158.19\left(\mathrm{C}_{8} \mathrm{H}_{16} \mathrm{NO}_{2}\right)$ (Schematic 2). These fragments are also in accordance with those reported by Kim et al. (2004) during the degradation of ERY in aqueous solutions.

The ERY molecule $\left(m / z 734, \mathrm{C}_{37} \mathrm{H}_{67} \mathrm{NO}_{13}\right)$ comprises a macrocyclic 14-membered lactone ring attached to two sugar moieties (a neutral sugar [cladinose] linked to position C-3 and a dimethylamino sugar [desosamine] linked to position C-5) (Chitneni et al., 2004; Deubel et al., 2006). The results of this study clearly demonstrated that the lactone ring of the ERY molecule was preserved in all the TPs identified herein, while the main structural alterations took place in the sugar moieties, as well as in some positions of the polyhydroxylactone ring. TP750 derived from the spontaneous demethylation (loss of $-\mathrm{CH}_{3}$ ) and hydroxylation (addition of $-\mathrm{OH}$ ) in position $\mathrm{C}-2$ of the lactone ring, which upon further dehydrogenation yielded TP748. The formation of TP720 can be explained by the net loss of the methoxy group $\left(-\mathrm{OCH}_{3}\right)$ of cladinose followed by the addition of a hydroxyl radical. TP718 was emerged from the liberation of the hydroxyl group at position C-12 of the linked saturated ring of the ERY molecule, while the formation of TP702 corresponds to the dehydroxylation (loss of $-\mathrm{OH}$ ) at position C-11 and subsequently to the dehydrogenation of the cladinose moiety. The aforementioned TPs have been also reported by Llorca et al. (2015) during the enzymatic degradation of ERY at laboratory scale in the presence of EreB esterase, as well as during the reaction of ERY with benzoyl peroxide (Haghedooren et al., 2006).

Three new TPs were also identified in the photo-treated samples which according to the authors' knowledge, these have not been reported either in biodegradation experiments or other advanced oxidation studies of ERY. As HO do not exhibit a high degree of selectivity towards various functional groups, isobaric compounds corresponding to positional isomers can be formed during

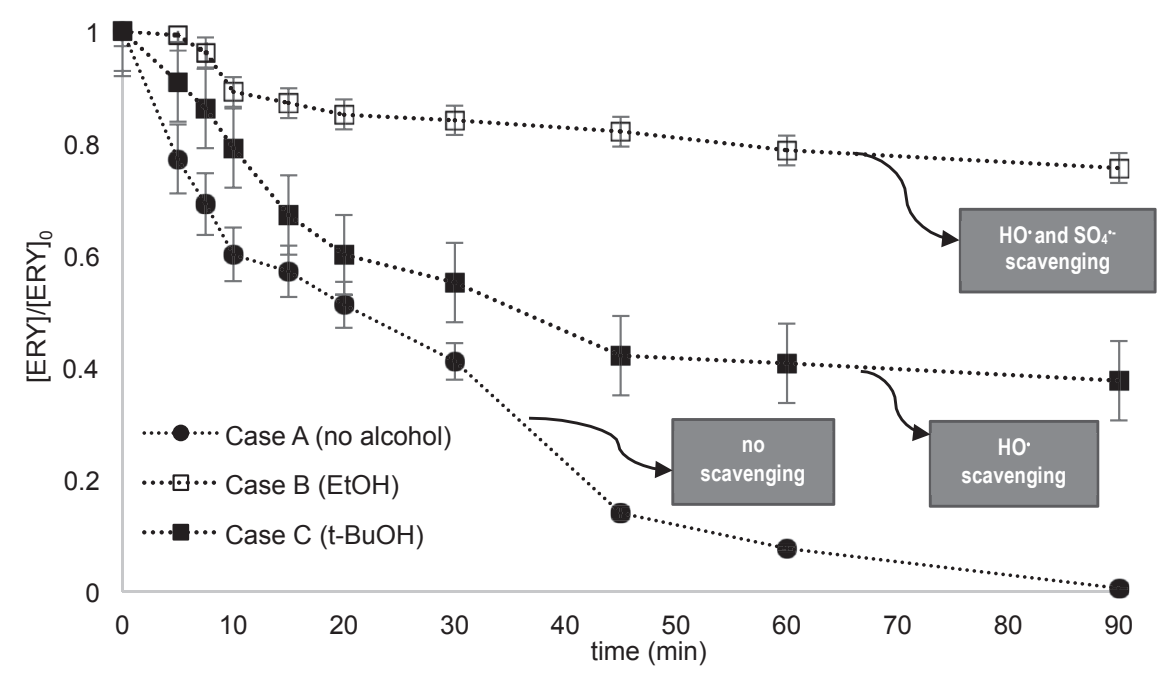

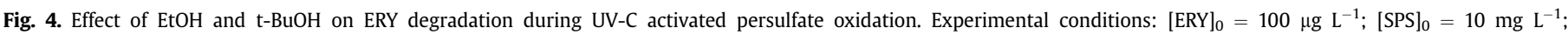
[alcohol] $=20 \mathrm{mM} ; \mathrm{T}=22 \pm 2{ }^{\circ} \mathrm{C}$. 


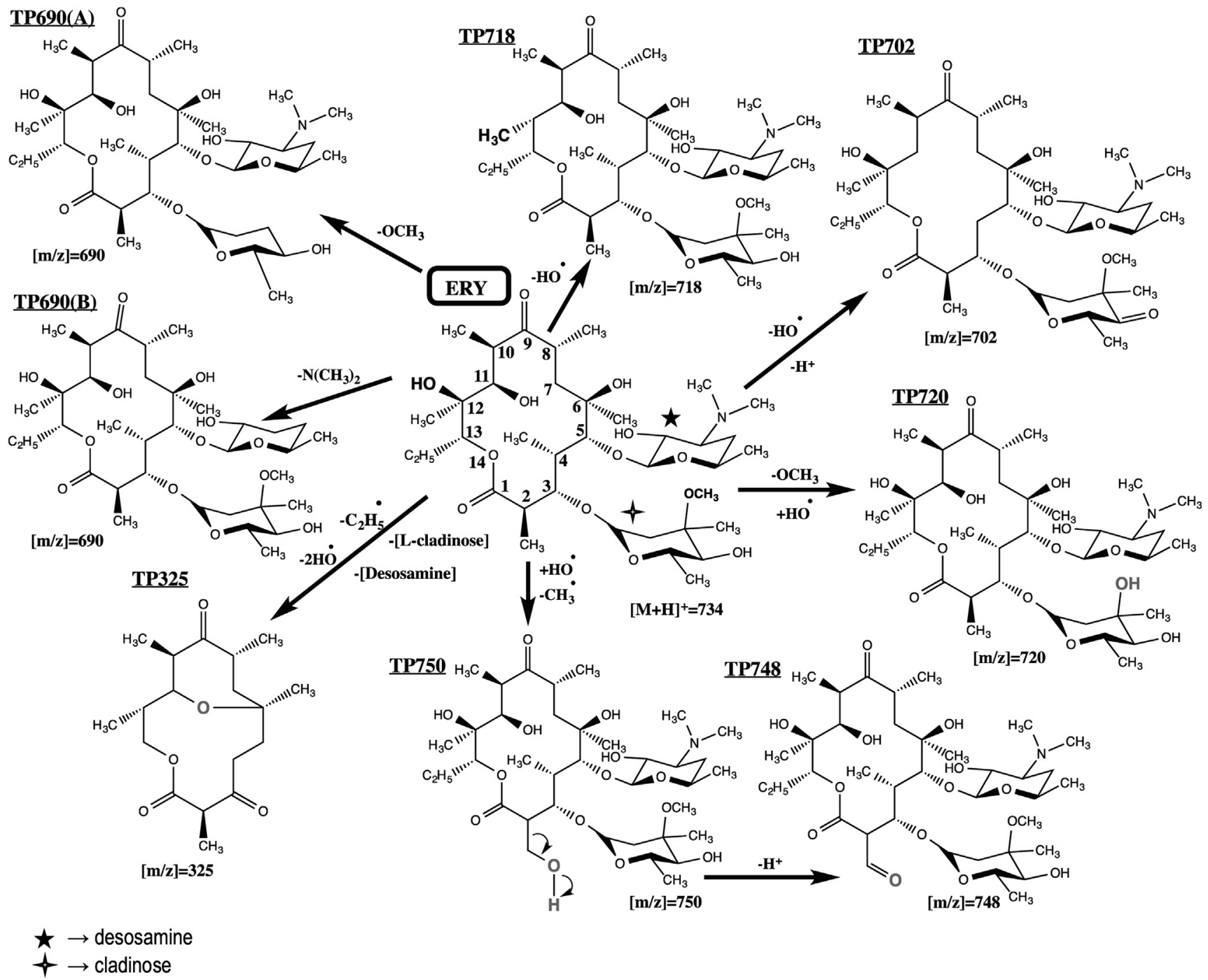

Scheme 1. Tentative transformation pathway of ERY degradation by UV-C-activated persulfate process.

oxidation. This was evidenced by the elucidation of two distinct positional isomers $(\operatorname{TP690}(\boldsymbol{A})$ and $\operatorname{TP690}(\boldsymbol{B}))$, whose differentiation was not feasible based on the UPLC-MS ${ }^{2}$ data. The formation of TP690(A) and TP690(B) can be ascribed to the loss of one methoxy group $\left(-\mathrm{OCH}_{3}\right)$ of the cladinose moiety and to the further elimination of the dimethylamine group $\left(-\mathrm{N}\left(\mathrm{CH}_{3}\right)_{2}\right)$ of desosamine, respectively. Finally, the molecular formula postulated for TP325 can been possibly attributed to the induction of multiple structural alterations, including internal dehydration of ERY at position C-11 of the lactone ring, followed by elimination of the ethyl moiety $\left(-\mathrm{C}_{2} \mathrm{H}_{5}\right)$, and the loss of both desosamine and cladinose.

The exact concentrations of the TPs cannot be calculated accurately due to the lack of pure analytical standards, thus a rudimentary quantification based on the intensity approach has been used in this study. The formation profile of the TPs was interpreted based on the relative intensity $\left(A_{T P} / A_{E R Y}\right)$, which is expressed as the ratio of the chromatographic peak area of the corresponding TP $\left(A_{T P}\right)$ with that of the concentration of a standard solution of the parent compound ( $A_{E R Y}$ ) (Fig. 5). It is evident that TP750, TP702 and TP748 emerged in the first stages of oxidation $(10 \mathrm{~min})$ and remained abundant in the reaction solution until the end of the treatment. From that time onwards, all the TPs appeared promptly, with TP718 being the most predominant one (higher relative intensity value). At the end of the treatment (90 min), all TPs reached their maximum intensity and this is in accordance with the fact that DOC was not efficiently reduced.

\subsection{Phytotoxicity assessment}

The phytotoxicity of the treated samples (under the optimum experimental conditions) towards $S$. alba, L. sativum and S. saccharatum was expressed as inhibition percentage in the seed germination (GI), root growth (RI) and shoot growth (SI). The phytotoxicity profile observed in the case of the treated wastewater samples spiked with the antibiotic $\left([E R Y]_{0}=100 \mu \mathrm{g} \mathrm{L}^{-1}\right)$ exhibited similar pattern with that obtained when exposing the plant species to the photo-treated samples in the absence of ERY (data not shown). Therefore, on this basis, it can be assumed that the seed germination and the growth of roots and shoots were not affected by the presence of ERY and its photo-oxidation products but the observed inhibition can be assigned to the oxidation of the various organic constituents prevailing in the $\mathrm{dE}_{\mathfrak{f}} \mathrm{OM}$ of the wastewater samples. The toxicity behaviour determined herein has been reported in a previous study of Michael et al. (2012), where two antibiotics (ofloxacin and trimethoprim, both spiked in CAS effluents at $100 \mu \mathrm{g} \mathrm{L}^{-1}$ ) were not found to be responsible for the high 


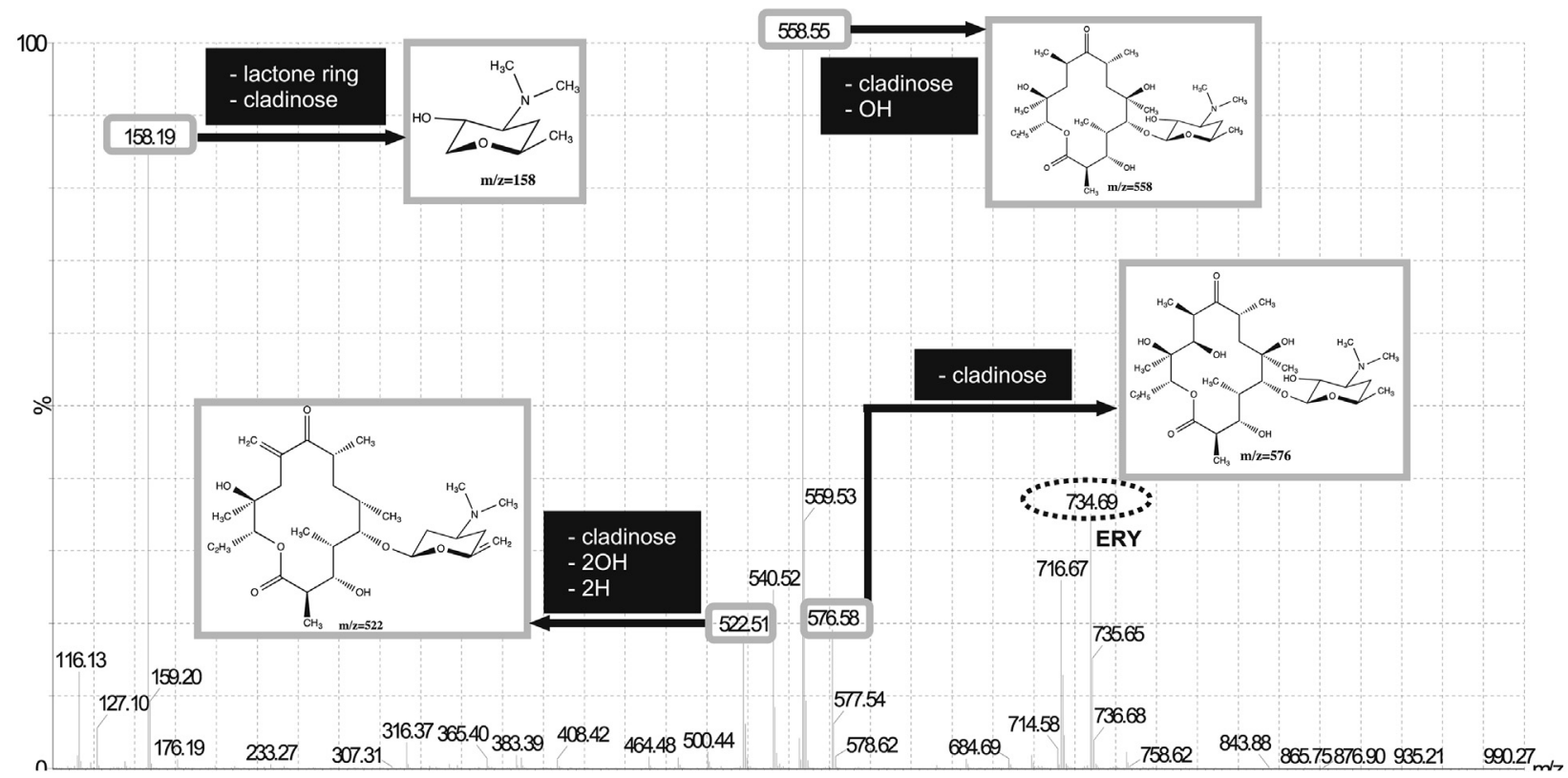

Scheme 2. Product ion $\mathrm{MS}^{2}$ spectrum of ERY-spiked wastewater solution $\left(10 \mathrm{mg} \mathrm{L}^{-1}\right)$.

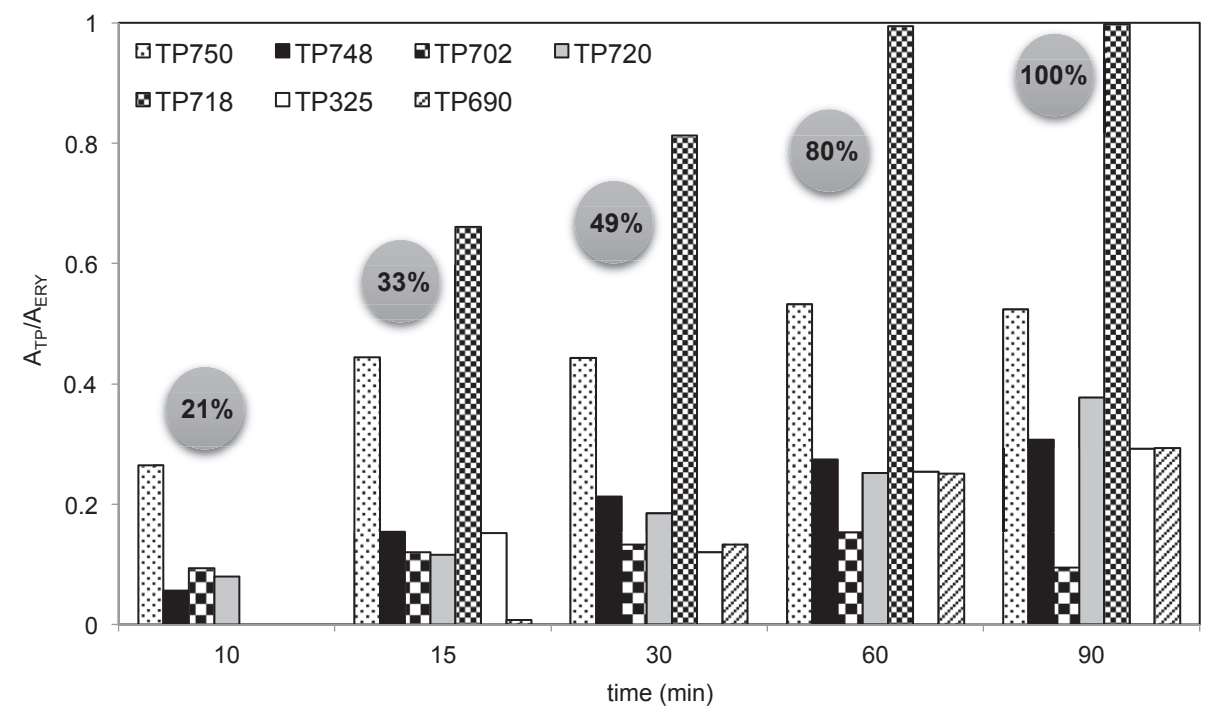

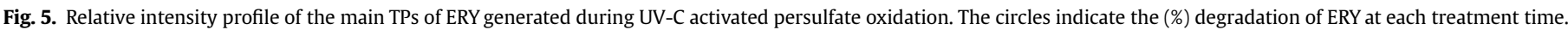

germination inhibition observed after the exposure of the seeds to the solar Fenton treated samples.

In general, the treated samples did not induce inhibition on the germination of the three plants; on the contrary, a favourable effect on seeds' germination was observed (negative inhibition values), which can be possibly assigned to the presence of nutrients and $\mathrm{dE}_{\mathrm{f}} \mathrm{OM}$ in the wastewater samples. Nonetheless, a phytotoxic effect against root and shoot growth was pronounced in all plant species as shown in Fig. 6 (a, b). The highest SI was recorded after 30 min of irradiation (S. alba [38\%], L. sativum [51\%], S. saccharatum [32\%]), implying the oxidation of $\mathrm{dE}_{\mathrm{f}} \mathrm{OM}$ and thus the concomitant formation of new organic entities with individual or/and synergistic phytotoxic effects. Finally, samples irradiated for 90 min displayed a decrease in SI down to 5\% level, indicating the removal (or further transformation) of the toxic oxidation products throughout the process (Fig. 6a). Similarly, RI acquired its maximum value within 30 min of treatment (S. alba [54\%], L. sativum [62\%], S. saccharatum [41\%]), and from that time onwards RI was significantly decreased to $5 \%, 10 \%$ and $8 \%$ for S. alba, L. sativum and S. saccharatum respectively (Fig. 6b). It was also observed that RI values were always higher compared to SI, indicating the susceptibility of roots compared to the shoots. Here it is noted that $\mathrm{dE}_{\mathrm{f}} \mathrm{OM}$ was monitored during the process in terms of DOC, which was only removed by $35 \%\left([D O C]_{\text {initial }}=8 \mathrm{mg} \mathrm{L}^{-1},[\mathrm{DOC}]_{\text {final }}=5 \mathrm{mg} \mathrm{L}^{-1}\right)$.

The phytotoxicity bioassay employed herein gives an 'overview' over the quality of the treated wastewater by the UV-C-activated persulfate oxidation process, and the above findings clearly demonstrate that the assessment of the potential biological potency of $\mathrm{dE}_{\mathrm{f}} \mathrm{OM}$ after advanced treatment should not be overlooked, especially in the case where wastewater is intended for reuse. It 

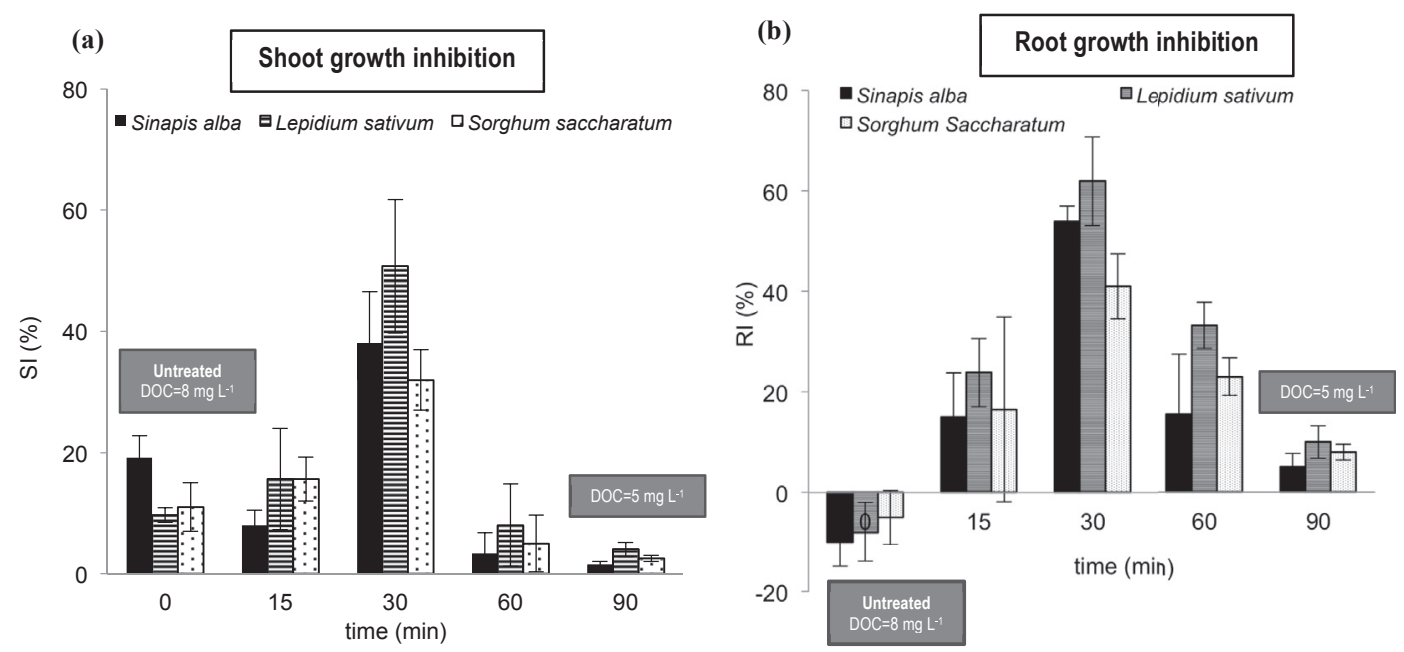

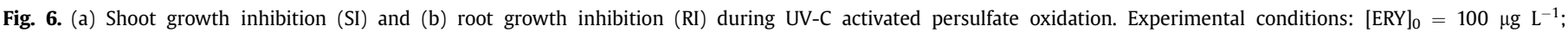
$[\mathrm{SPS}]_{0}=10 \mathrm{mg} \mathrm{L}^{-1} ; \mathrm{pH}=7 ; \mathrm{T}=22 \pm 2{ }^{\circ} \mathrm{C}$.

seems that the sulfate radical-based oxidation process is efficient in removing phytotoxicity, however the results obtained from only one bioassay cannot extrapolate concrete conclusions regarding the biological effect of the $\mathrm{dE}_{\mathrm{f}} \mathrm{OM}$ oxidation products.

\subsection{Removal of ERY-resistant E. coli during UV-C activated persulfate oxidation}

E. coli are frequently released into the environment via wastewater discharges and reuse applications and they are often used as reliable indicators of microbial quality in various aquatic compartments and for monitoring antibiotic resistance due to their ubiquity in a wide range of hosts and ability of acquiring resistance easily (European Antimicrobial Resistance Surveillance Network EARS-Net). Some studies have identified that the main mechanism that appears to be responsible for $E$. coli becoming resistant to antibiotics is the production of extended-spectrum $\beta$ lactamases (ESBLs), known as the CTX-M enzymes (Pitout and Laupland, 2008). The high prevalence of ERY-resistant bacteria (with predominant species being Enterococcus faecium and Enterococcus faecalis) in WWTPs effluents and surface water has been reported by many authors (Guo et al., 2013b, 2015; Yuan et al., 2015). Nevertheless, among the antibiotic-resistant $E$. coli, those that are resistant to ERY remain the least studied (Guo et al., 2013a,b). ERY resistance is mediated by several different mechanisms, including expression of specific short peptides in bacterial cells, erm methylases production and efflux pumps (Gaynor and Mankin, 2003; Zheng et al., 2009).

The evolution profile of $E$. coli in the treated samples expressed as $\mathrm{CFU} / \mathrm{CFU}_{0}$ against treatment time is shown in Fig. 7. It was observed that total (i.e. medium without ERY) and ERY-resistant E. coli (i.e. medium with ERY) declined with treatment time, while the removal rate of $E$. coli in the culture medium enriched with ERY, was significantly lower compared to that observed in the medium without the antibiotic. The results in Fig. 7 show that total E. coli inactivation was as high as three log units just after 5 min of irradiation, while a two-log reduction of ERY-resistant $E$. coli occurred at the same time. After 45 and 30 min of treatment there was a complete removal of $E$. coli in the media with and without ERY respectively, with CFU counted being below the limit of detection. This indicates efficient removal of ERY-resistant E. coli and at the same time, disinfection of the wastewater matrix from all $E$. coli, as shown in the medium not supplemented with the antibiotic. The high efficiency of the UV-C/SPS treatment in removing total cultivable and antibiotic-resistant $E$. coli is synergistically supported by the addition to the treatment solution of SPS, which generates $\mathrm{SO}_{4}{ }^{-}$(and subsequently $\mathrm{HO} \cdot$ depending on solution $\mathrm{pH}$ ) upon photolysis by $254 \mathrm{~nm}$ irradiation, which can contribute to the inactivation of $E$. coli. An additional experiment was carried out in the absence of SPS (UV-C irradiation alone) in order to confirm the synergistic effect of both radicals in removing E. coli from the wastewater solution. The results (inset of Fig. 6) clearly demonstrated the ability of UV-C irradiation treatment to reduce both total and ERY-resistant $E$. coli over time (45 and 90 min, respectively). Nevertheless, the removal rate was significantly lower compared to that observed in the presence of the oxidant.

According to the authors' knowledge, there are no available studies on the removal of ERY-resistant bacteria by $\mathrm{SO}_{4}{ }^{-}$-based oxidation processes. Also, there is limited scientific literature surrounding the removal of ERY-resistant bacteria during the application of UV-driven advanced treatment. Guo et al. (2013a,b) reported the high efficiency of UV treatment in removing ERYresistant heterotrophic bacteria at a UV fluence of $5 \mathrm{~mJ} \mathrm{~cm} \mathrm{~cm}^{-2}$, with the corresponding $\log$ reduction being $1.4 \pm 0.1$. When the fluence increased to 20 and $50 \mathrm{~mJ} \mathrm{~cm}^{-2}$, the counts of total resistant bacteria were below $1 \mathrm{CFU} \mathrm{mL}^{-1}$. In general, to date there have been few and conflicting reports regarding the efficiency of UV-based processes in removing antibiotic-resistant bacteria (ARB) from wastewater. For example, Conner-Kerr et al. (1998) reported the effective inactivation of methicillin-resistant strain of Staphylococcus aureus and vancomycin-resistant E. faecalis following UV

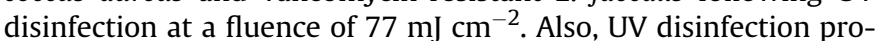
cess resulted in a total reduction of the proportion of $E$. coli which were resistant towards amoxicillin, ciprofloxacin and sulfamethoxazole after $60 \mathrm{~min}$ of irradiation $\left(1.25 \times 10^{4} \mu \mathrm{W} \mathrm{s} \mathrm{cm}{ }^{-2}\right.$ ) (Rizzo et al., 2013b). On the other hand, UV process did not contribute to significant reduction of tetracycline- and sulphonamideresistant E. coli (Munir et al., 2011).

It is important to highlight that the effective inactivation of ARB in any wastewater treatment process does not imply elimination of antibiotic resistance in wastewater, as antibiotic-resistance genes (ARG) and mobile genetic elements (e.g. plasmids carrying ARG) which persist in wastewater and can be transferred into new hosts, need to be considered as well. From the TPs point of view, one can assume that these 'new' compounds may possess their own 


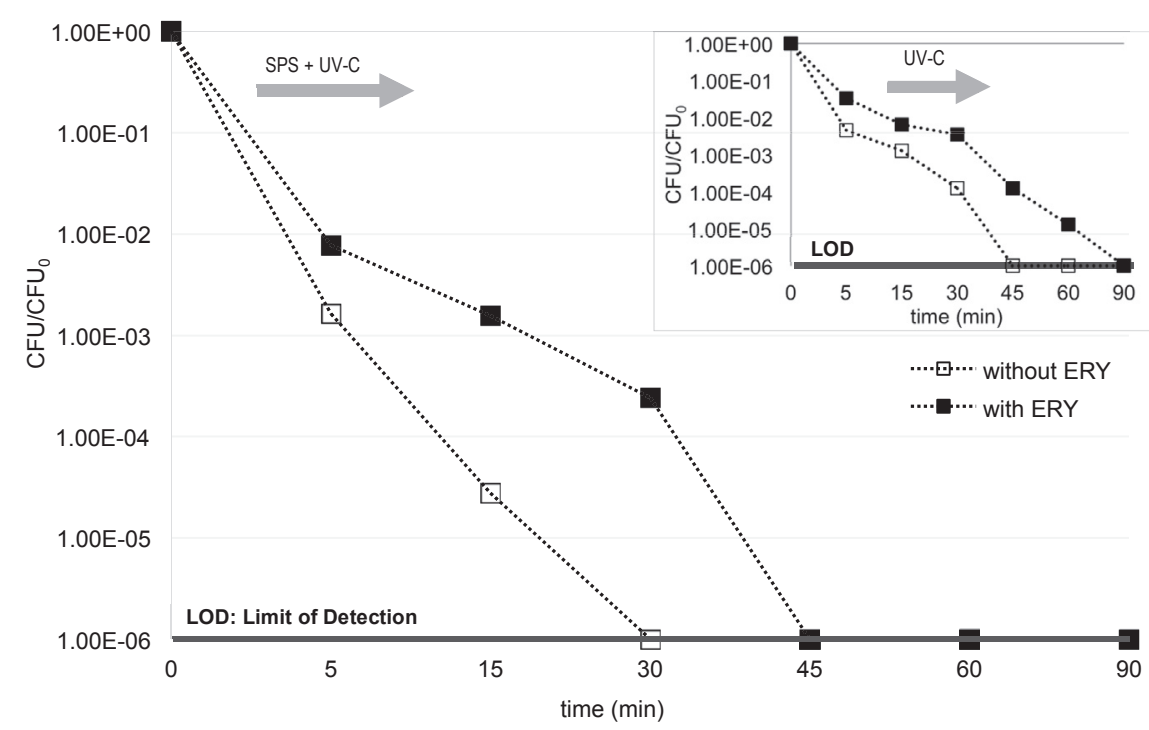

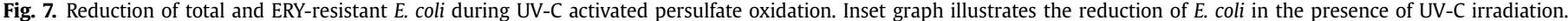
Experimental conditions: [ERY $]_{0}=100 \mu \mathrm{g} \mathrm{L}^{-1} ;[\mathrm{SPS}]_{0}=10 \mathrm{mg} \mathrm{L}^{-1} ; \mathrm{pH}=8 ; \mathrm{T}=22 \pm 2{ }^{\circ} \mathrm{C}$.

antimicrobial activity contributing thus to the overall evolution of antibiotic resistance in bacterial strains of the treated wastewater samples. In this study, it was clearly demonstrated that the 14membered lactone ring of ERY along with the two active sugar moieties were preserved during degradation (except TP325, loss of both cladinose and desosamine), resulting thus in the formation of TPs with similar structural characteristics. It has been reported that the desosamine group of ERY can potentially interact with nucleotides through the formation of hydrogen bonds, while hydrophobic interactions between the lactone ring and ribosome may also occur (Gaynor and Mankin, 2003). Thus, it can be presumed that the TPs identified herein may preserve the same mode of action with that of the parent compound. However, the lack of analytical standards constitutes a major obstacle in verifying such statements.

\section{Conclusions}

In the framework of implementing safe wastewater reuse schemes, efficient treatment technologies should be applied for wastewater remediation to meet the current challenges associated with antibiotics and antibiotic-resistant bacteria spread into the environment. Overall, this study clearly demonstrated the high efficiency of UV-C activated persulfate oxidation treatment in removing ERY from wastewater effluents, as well as E. coli carrying resistance to ERY. The experimental results revealed that the degradation efficiency increased with increasing oxidant dosage, and that inherent $\mathrm{pH}$ conditions enhanced the antibiotic degradation. ERY degradation was found to obey a pseudo-first-order kinetic law under the various experimental conditions applied. From the kinetic point of view, the degradation of ERY exhibited different pattern among the aqueous matrices investigated, with the apparent rate constant being appreciably higher in UPW compared to the other matrices, suggesting that the radicals generated in the reaction solution were scavenged by the various constituents present in BW, HA and WW. The degradation of ERY in BW progressed at a slower rate in relation to UPW due to its high inorganic content, while SMPs were assumed to be responsible for the slower antibiotic degradation in WW compared to $\mathrm{HA} \mathrm{SO}_{4}{ }^{-}$- were found to be the predominant radical species formed in the UV-C/SPS system yielding 63\% degradation of ERY, whereas the contribution of $\mathrm{HO}$ • was estimated to be much lower. The transformation of ERY during the oxidation process was denoted through the identification of seven new organic entities, whose molecular structure retained the basic lactone ring of the ERY molecule. Hydroxylation, demethylation and dehydrogenation were considered as the principal reaction mechanisms during the oxidation of ERY, while structural alterations have also been occurred in the cladinose and desosamine moieties of the molecule. Further studies are needed to appraise whether the TPs identified during the oxidation maintain the antibiotic activity of ERY, considering the fact that most of the TPs exhibited similar structural characteristics with the parent compound. $\mathrm{dE}_{\mathrm{f}} \mathrm{OM}$ and their associated-oxidation products generated during treatment were responsible for the low mineralization of the treated solutions, as well as for the evolution of phytotoxicity. UV-C/SPS treatment was able to achieve a reduction of the inhibition percentage in root and shoot growth of the seeds, while at the same time the process resulted in complete elimination of $E$. coli, including those resistant to ERY.

The outlook of the UV-C/SPS technology with regard to antibiotics' and ARB removal is promising, however many aspects still remain obscure. $\mathrm{dE}_{\mathfrak{f}} \mathrm{OM}$ and its oxidation products seem to affect greatly the process performance and hence, further studies should be developed to reveal the $\mathrm{dE}_{\mathrm{f}} \mathrm{OM}$-associated compounds' nature and characteristics and their biological potency. In addition, an integrated assessment of the treated flow using a battery of effectbased bioassays in the context of safe wastewater reuse is essential. Finally, the evaluation of the process performance in removing other types of bacteria, as well as ARG, should be addressed.

\section{Acknowledgements}

This work was prepared in the framework of the KOY $\Lambda$ TOYPA/ BENS/0412/24 research project 'Closing Gaps of Knowledge with respect to Advanced Chemical Oxidation Processes for the Removal of Contaminants of Emerging Concern (GAPS)', implemented within the national framework program for research, technological development and innovation 'DESMH 2009-2010'. Nireas-IWRC (NEA YПO $\Delta \mathrm{OMH} / \Sigma \mathrm{TPATH} / 0308 / 09$ ) is co-financed by the Republic of Cyprus and the European Regional Development Fund through the Research Promotion Foundation of Cyprus. The authors would like to acknowledge the COST-European Cooperation in 
Science and Technology Action ES1403: New and emerging challenges and opportunities in wastewater reuse (NEREUS), for stimulating the work implemented in the manuscript.

\section{Disclaimer}

The content of this article is the authors' responsibility and neither COST nor any person acting on its behalf is responsible for the use, which might be made of the information contained in it.

\section{References}

Anipsitakis, G.P., Dionysiou, D.D., 2004. Radical generation by the interaction of transition metals with common oxidants. Environ. Sci. Technol. 38, 3705-3712.

Babić, S., Horvat, A.J.M., Pavlović, D.M., Kaštelan-Macan, M., 2007. Determination of pKa values of active pharmaceutical ingredients. Trends Anal. Chem. 26, 1043-1061.

Batchu, S.R., Panditi, V.R., O'Shea, K.E., Gardinali, P.R., 2014. Photodegradation of antibiotics under simulated solar radiation: implications for their environmental fate. Sci. Total Environ. 470-471, 299-310.

Berendonk, T.U., Manaia, C.M., Merlin, C., Fatta-Kassinos, D., Cytryn, E., Walsh, F. Bürgmann, H., Sørum, H., Norström, M., Pons, M.N., Kreuzinger, N., Huovinen, P. Stefani, S., Schwartz, T., Kisand, V., Baquero, F., Martinez, J.L., 2015. Tackling antibiotic resistance: the environmental framework. Nat. Rev. Microbiol. 13, $310-317$.

CEN/SABE ENV Team, 2014. Environmental Monitoring Strategy Team. ENV N 301.

Chen, N., Huang, L.J., Liu, N., Liu, Y., Wang, S.F., 2013. Analysis of the effect of erythromycin wastewater degradation by Fenton Method. Asian J. Chem. 25, $7208-7210$.

Chitneni, S.K., Govaerts, C., Adams, E., Van Schepdael, A., Hoogmartens, J., 2004. Identification of impurities in erythromycin by liquid chromatography-mass spectrometric detection. J. Chromatogr. A 1056, 111-120.

Clesceri, L.S., Greenberg, A.E., Eaton, A.D., 1998. Standard Methods for the Examination of Water and Wastewater, 20th ed. American Public Health Association, American Water Works Association, Water Environment Federation, Baltimore Maryland.

Conner-Kerr, T.A., Sullivan, P.K., Gaillard, J., Franklin, M.E., Jones, R.M., 1998. The effects of ultraviolet radiation on antibiotic-resistant bacteria in vitro. Ostomy/ wound Manag. 44 (10), 50-56.

Deng, J., Shao, Y., Gao, N., Xia, S., Tan, C., Zhou, S., Hu, X., 2013. Degradation of the antiepileptic drug carbamazepine upon different UV-based advanced oxidation processes in water. Chem. Eng. J. 222, 150-158.

Deubel, A., Fandino, A.S., Sörgel, F., Holzgrabe, U., 2006. Determination of erythromycin and related substances in commercial samples using liquid chromatography/ion trap mass spectrometry. J. Chromatogr. A 1136, 39-47.

EU, 2015/495. Commission Implementing Decision Establishing a Watch List of Substances for Union-wide Monitoring in the Field of Water Policy Pursuant to Directive 2008/105/EC of the European Parliament and of the Council, http:// eur-lex.europa.eu/legal-content/EN/TXT/PDF/?uri=CELEX: 32015D0495\& from $=$ EN.

European Antimicrobial Resistance Surveillance Network (EARS-Net), 2015. Antimicrobial Resistance (AMR) Reporting Protocol. http://ecdc.europa.eu/en/ activities/surveillance/EARS-Net/Documents/2015-EARS-Net-reportingprotocol.pdf.

Fang, G., Gao, J., Dionysiou, D.D., Liu, C., Zhou, D., 2013. Activation of persulfate by quinones: free radical reactions and implication for the degradation of PCBs. Environ. Sci. Technol. 47, 4605-4611.

Fatta-Kassinos, D., Manaia, C., Berendonk, T.U., Cytryn, E., Bayona, J., Chefetz, B. Slobodnik, J., Kreuzinger, N., Rizzo, L., Malato, S., Lundy, L., Ledin, A., 2015. COST Action ES1403: new and emerging challenges and opportunities in wastewater REUSe (NEREUS). Environ. Sci. Pollut. Res. 22, 7183-7186.

Frontistis, Z., Hapeshi, E., Fatta-Kassinos, D., Mantzavinos, D., 2015. Ultravioletactivated persulfate oxidation of methyl orange: a comparison between artificial neural networks and factorial design for process modelling. Photochem. Photobiol. Sci. 14, 528-535.

Gao, Y., Gao, N., Deng, Y., Yang, Y., Ma, Y., 2012. Ultraviolet (UV) light-activated persulfate oxidation of sulfamethazine in water. Chem. Eng. J. 195-196, $248-253$.

Gaynor, M., Mankin, A.S., 2003. Macrolide antibiotics: binding site, mechanism of action, resistance. Curr. Top. Med. Chem. 3, 949-960.

Ghauch, A., Tuqan, A.M., Kibbi, N., 2012. Ibuprofen removal by heated persulfate in aqueous solution: a kinetics study. Chem. Eng. J. 197, 483-492.

González-Pleiter, M., Gonzalo, S., Rodea-Palomares, I., Leganés, F., Rosal, R., Boltes, K., Marco, E., Fernández-Piñas, F., 2013. Toxicity of five antibiotics and their mixtures towards photosynthetic aquatic organisms: implications for environmental risk assessment. Water Res. 47, 2050-2064.

Guan, Y.H., Ma, J., Li, X.C., Fang, J.Y., Chen, L.W., 2011. Influence of pH on the formation of sulfate and hydroxyl radicals in the UV/peroxymonosulfate system. Environ. Sci. Technol. 45, 9308-9314.

Guo, M.T., Yuan, Q.B., Yang, J., 2013a. Ultraviolet reduction of erythromycin and tetracycline resistant heterotrophic bacteria and their resistance genes in municipal wastewater. Chemosphere 93, 2864-2868.

Guo, M.T., Yuan, Q.B., Yang, J., 2013b. Microbial selectivity of UV treatment on antibiotic resistant heterotrophic bacteria in secondary effluents of a municipal wastewater treatment plant. Water Res. 47, 6388-6394.

Guo, M.T., Yuan, Q.B., Yang, J., 2015. Insights into the amplification of bacterial resistance to erythromycin in activated sludge. Chemosphere 136, 79-85.

Haghedooren, E., Raju, K.K.R.B.V.S., Dehouck, P., Govaerts, C., Van Schepdael, A., Hoogmartens, J., Adams, E., 2006. Investigation of degradation products in a topical gel containing erythromycin and benzoyl peroxide by liquid chromatography-mass spectrometry. J. Pharm. Biomed. Anal. 41, 165-175.

He, X., de la Cruz, A.A., Dionysiou, D.D., 2013. Destruction of cyanobacterial toxin cylindrospermopsin by hydroxyl radicals and sulfate radicals using UV-254 nm activation of hydrogen peroxide, persulfate and peroxymonosulfate. J. Photochem. Photobiol. A Chem. 251, 160-166.

Ji, K., Kim, S., Han, S., Seo, J., Lee, S., Park, Y., Choi, K., Kho, Y.L., Kim, P.G., Park, J., Choi, K., 2012. Risk assessment of chlortetracycline, oxytetracycline, sulfamethazine, sulfathiazole, and erythromycin in aquatic environment: are the current environmental concentrations safe? Ecotoxicology 21, 2031-2050.

Keen, O.S., Linden, K.G., 2013. Degradation of antibiotic activity during UV/ $\mathrm{H}_{2} \mathrm{O}_{2}$ advanced oxidation and photolysis in wastewater effluent. Environ. Sci. Technol. 47, 13020-13030.

Khan, J.A., He, X., Khan, H.M., Shah, N.S., Dionysiou, D.D., 2013. Oxidative degradation of atrazine in aqueous solution by $\mathrm{UV} / \mathrm{H}_{2} \mathrm{O}_{2} / \mathrm{Fe}^{2+}, \mathrm{UV} / \mathrm{S}_{2} \mathrm{O}_{8}^{2-} / \mathrm{Fe}^{2+}$ and $\mathrm{UV} /$ $\mathrm{HSO}_{5}^{-} / \mathrm{Fe}^{2+}$ processes: a comparative study. Chem. Eng. J. 218, 376-383.

Khan, J.A., He, X., Shah, N.S., Khan, H.M., Hapeshi, E., Fatta-Kassinos, D., Dionysiou, D.D., 2014. Kinetic and mechanism investigation on the photochemical degradation of atrazine with activated $\mathrm{H}_{2} \mathrm{O}_{2}, \mathrm{~S}_{2} \mathrm{O}_{8}^{2-}$ and $\mathrm{HSO}_{5}^{-}$. Chem. Eng. J. 252, 393-403.

Kim, Y.H., Heinze, T.M., Beger, R., Pothuluri, J.V., Cerniglia, C.E., 2004. A kinetic study on the degradation of erythromycin A in aqueous solution. Int. J. Pharm. 271, 63-76.

Kim, I., Yamashita, N., Tanaka, H., 2009. Performance of UV and UV/ $\mathrm{H}_{2} \mathrm{O}_{2}$ processes for the removal of pharmaceuticals detected in secondary effluent of a sewage treatment plant in Japan. J. Hazard. Mater. 166, 1134-1140.

Liang, C., Wang, Z.S., Bruell, C.J., 2007. Influence of pH on persulfate oxidation of TCE at ambient temperatures. Chemosphere 66, 106-113.

Lin, C.C., Wu, M.S., 2014. Degradation of ciprofloxacin by $\mathrm{UV} / \mathrm{S}_{2} \mathrm{O}_{8}^{2-}$ process in a large photoreactor. J. Photochem. Photobiol. A Chem. 285, 1-6.

Lin, A.Y.C., Lin, C.F., Chiou, J.M., Hong, P.K.A., 2009. $\mathrm{O}_{3}$ and $\mathrm{O}_{3} / \mathrm{H}_{2} \mathrm{O}_{2}$ treatment of sulfonamide and macrolide antibiotics in wastewater. J. Hazard. Mater. 171, $452-458$.

Liu, B.Y., Nie, X.P., Liu, W.Q., Snoeijs, P., Guan, C., Tsui, M.T.K., 2011. Toxic effects of erythromycin, ciprofloxacin and sulfamethoxazole on photosynthetic apparatus in Selenastrum capricornutum. Ecotoxicol. Environ. Saf. 74, 1027-1035.

Llorca, M., Rodríguez-Mozaz, S., Couillerot, O., Panigoni, K., de Gunzburg, J., Bayer, S., Czaja, R., Barceló, D., 2015. Identification of new transformation products during enzymatic treatment of tetracycline and erythromycin antibiotics at laboratory scale by an on-line turbulent flow liquid-chromatography coupled to a high resolution mass spectrometer LTQ-Orbitrap. Chemosphere 119, 90-98.

Mahdi-Ahmed, M., Chiron, S., 2014. Ciprofloxacin oxidation by UV-C activated peroxymonosulfate in wastewater. J. Hazard. Mater. s265, 41-46.

Michael, I., Hapeshi, E., Michael, C., Varela, A.R., Kyriakou, S., Manaia, C., FattaKassinos, D., 2012. Effectiveness of solar Fenton process on abatement of antibiotics at a pilot plant scale: degradation kinetics, ecotoxicity assessment and removal of antibiotic resistant enterococci. Water Res. 46, 5621-5634.

Michael, I., Rizzo, L., McArdell, C., Manaia, C., Merlin, C., Schwartz, T., Dagot, C., FattaKassinos, D., 2013. Urban wastewater treatment plants as hotspots for the release of antibiotics in the environment: a review. Water Res. 47 (3), 957-995.

Michael-Kordatou, C., Michael, X., Duan, X., He, D., Dionysiou, M.A., Mills, FattaKassinos, D., 2015. Effluent organic matter: characteristics and potential implications in wastewater treatment and reuse applications. Water Res. 77, 213-248.

Monteagudo, J.M., Durán, A., González, R., Expósito, A.J., 2015. In situ chemical oxidation of carbamazepine solutions using persulfatesimultaneously activated by heat energy, UV light, $\mathrm{Fe}^{2+}$ ions, and $\mathrm{H}_{2} \mathrm{O}_{2}$. Appl. Catal. B Environ. 176, $120-129$.

Munir, M., Wong, K., Xagoraraki, I., 2011. Release of antibiotic resistant bacteria and genes in the effluent and biosolids of five wastewater utilities in Michigan. Water Res. 45 (2), 681-693.

Muñoz, I., Gómez-Ramos, M.J., Agüera, A., García-Reyes, J.F., Molina-Díaz, A., Fernández-Alba, A.R., 2009. Chemical evaluation of contaminants in wastewater effluents and the environmental risk of reusing effluents in agriculture. Trends Anal. Chem. 28, 676-694.

Nie, X.P., Liu, B.Y., Yu, H.J., Liu, W.Q., Yang, Y.F., 2013. Toxic effects of erythromycin, ciprofloxacin and sulfamethoxazole exposure to the antioxidant system in Pseudokirchneriella subcapitata. Environ. Pollut. 172, 23-32.

Nfodzo, P., Choi, H., 2011. Triclosan decomposition by sulfate radicals: effects of oxidant and metal doses. Chem. Eng. J. 174 (2), 629-634.

Novo, A., Manaia, C.M., 2010. Factors influencing antibiotic resistance burden in municipal wastewater treatment plants. Appl. Microbiol. Biotechnol. 87, 1157-1166.

Olmez-Hanci, T., Arslan-Alaton, I., Genc, B., 2013. Bisphenol A treatment by the hot persulfate process: oxidation products and acute toxicity. J. Hazard. Mater. 263, $283-290$.

Pitout, J., Laupland, K.B., 2008. Extended-spectrum $\beta$-lactamase-producing 
Enterobacteriaceae: an emerging public-health concern. Lancet Infect. Dis. 8, 159-166.

Pomati, F., Netting, A.G., Calamari, D., Neilan, B.A., 2004. Effects of erythromycin, tetracycline and ibuprofen on the growth of Synechocystis sp. and Lemna minor. Aquat. Toxicol. 67, 387-396.

Qi, C., Liu, X., Lin, C., Zhang, X., Ma, J., Tan, H., Ye, W., 2014. Degradation of sulfamethoxazole by microwave-activated persulfate: kinetics, mechanism and acute toxicity. Chem. Eng. J. 249, 6-14.

Rizzo, L., Manaia, C., Merlin, C., Schwartz, T., Dagot, C., Ploy, M., Michael, I., FattaKassinos, D., 2013a. Urban wastewater treatment plants as hotspots for antibiotic resistant bacteria and genes spread into the environment: a review. Sci. Total Environ. 447, 345-360.

Rizzo, L., Fiorentino, A., Anselmo, A., 2013b. Advanced treatment of urban wastewater by UV radiation: effect on antibiotics and antibiotic-resistant E. coli strains. Chemosphere 92 (2), 171-176.

Saien, J., Osali, M., Soleymani, A.R., 2014. UV/persulfate and UV/hydrogen peroxide processes for the treatment of salicylic acid: effect of operating parameters, kinetic, and energy consumption. Desalination Water Treat. http://dx.doi.org/ 10.1080/19443994.2014.963156.

Serrano, D., Suárez, S., Lema, J.M., Omil, F., 2011. Removal of persistent pharmaceutical micropollutants from sewage by addition of PAC in a sequential membrane bioreactor. Water Res. 45, 5323-5333.

Sirtori, C., Agüera, A., Gernjak, W., Malato, S., 2010. Effect of water-matrix composition on Trimethoprim solar photodegradation kinetics and pathways. Water Res. 44, 2735-2744.

Tan, C., Gao, N., Deng, Y., Zhang, Y., Sui, M., Deng, J., Zhou, S., 2013. Degradation of antipyrine by UV, UV/ $\mathrm{H}_{2} \mathrm{O}_{2}$ and UV/PS. J. Hazard. Mater. 260, 1008-1016.

Ternes, T.A. Stuber, J. Herrmann, N., McDowell, D., Ried, A., Kampmann, M. Teiser, B., 2003. Ozonation: a tool for removal of pharmaceuticals, contrast media and musk fragrances from wastewater? Water Res. 37, 1976-1982.

The White House, 2014. National Strategy for Combating Antibiotic-resistant Bacteria. http://www.whitehouse.gov/sites/default/files/docs/carb_national strategy.pdf.

Vaz-Moreira, I., Nunes, O.C., Manaia, C.M., 2014. Bacterial diversity and antibiotic resistance in water habitats: searching the links with the human microbiome. FEMS Microbiol. Rev. 38, 761-778. http://dx.doi.org/10.1111/1574-6976.12062.

Xekoukoulotakis, N.P., Xinidis, N., Chroni, M., Mantzavinos, D., Venieri, D. Hapeshi, E., Fatta-Kassinos, D., 2010. UV-A/TiO 2 photocatalytic decomposition of erythromycin in water: factors affecting mineralization and antibiotic activity. Catal. Today 151, 29-33.

Yuan, Q.B., Guo, M.T., Yang, J., 2015. Fate of antibiotic resistant bacteria and genes during wastewater chlorination: implication for antibiotic resistance control. PLoS One. http://dx.doi.org/10.1371/journal.pone.0119403.

Zhang, Q., Chen, J., Dai, C., Zhang, Y., Zhou, X., 2014. Degradation of carbamazepine and toxicity evaluation using the UV/persulfate process in aqueous solution. J. Chem. Technol. Biotechnol. 90, 701-708.

Zhang, X.X., Zhang, T., Fang, H.H.P., 2009. Antibiotic resistance genes in water environment. Appl. Microbiol. Biotechnol. 82, 397-414.

Zheng, J., Sagar, V., Smolinsky, A., Bourke, C., LaRonde-LeBlanc, N., Cropp, T.A., 2009. Structure and function of the macrolide biosensor protein, MphR(A), with and without erythromycin. J. Mol. Biol. 387, 1250-1260. 